\title{
Physical properties and concentration of aerosol particles over the Amazon tropical forest during background and biomass burning conditions
}

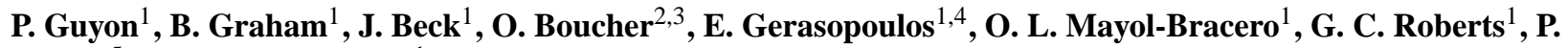 \\ Artaxo $^{5}$, and M. O. Andreae ${ }^{1}$ \\ ${ }^{1}$ Max Planck Institute for Chemistry, Department of Biogeochemistry, Mainz, Germany \\ ${ }^{2}$ Max Planck Institute for Chemistry, Department of Atmospheric Chemistry, Mainz, Germany \\ ${ }^{3}$ Laboratoire d'Optique Atmosphérique, CNRSUMR 8518, Villeneuve d'Ascq, France \\ ${ }^{4}$ Nuclear Physics Department, Aristotle University of Thessaloniki, Thessaloniki, Greece \\ ${ }^{5}$ Institute for Physics, University of São Paulo, São Paulo, Brazil
}

Received: 13 January 2003 - Published in Atmos. Chem. Phys. Discuss.: 13 March 2003

Revised: 13 June 2003 - Accepted: 1 July 2003 - Published: 8 July 2003

\begin{abstract}
We investigated the size distribution, scattering and absorption properties of Amazonian aerosols and the optical thickness of the aerosol layer under the pristine background conditions typical of the wet season, as well as during the biomass-burning-influenced dry season. The measurements were made during two campaigns in 1999 as part of the European contribution to the Large-Scale BiosphereAtmosphere Experiment in Amazonia (LBA-EUSTACH). In moving from the wet to the dry season, median particle numbers were observed to increase from values comparable to those of the remote marine boundary layer $\left(\sim 400 \mathrm{~cm}^{-3}\right)$ to values more commonly associated with urban smog $\left(\sim 4000 \mathrm{~cm}^{-3}\right)$, due to a massive injection of submicron smoke particles. Aerosol optical depths at $500 \mathrm{~nm}$ increased from 0.05 to 0.8 on average, reaching a value of 2 during the dry season. Scattering and absorption coefficients, measured at $550 \mathrm{~nm}$, showed a concomitant increase from average values of 6.8 and $0.4 \mathrm{Mm}^{-1}$ to values of 91 and $10 \mathrm{Mm}^{-1}$, respectively, corresponding to an estimated decrease in singlescattering albedo from ca. 0.97 to 0.91 . The roughly tenfold increase in many of the measured parameters attests to the dramatic effect that extensive seasonal biomass burning (deforestation, pasture cleaning) is having on the composition and properties of aerosols over Amazonia. The potential exists for these changes to impact on regional and global climate through changes to the extinction of solar radiation as well as the alteration of cloud properties.
\end{abstract}

Correspondence to: P. Guyon

(guyon@mpch-mainz.mpg.de)

\section{Introduction}

Solar radiation is modified when passing through the atmosphere by two main processes: light scattering and light absorption. Light scattering is a redistribution of the incident light in nonparallel directions, whilst light absorption consists of a conversion of the incident light into thermal energy. The attenuation of light by these processes has important climatic consequences (Andreae and Crutzen, 1997; IPCC, 2001).

Trace gases like $\mathrm{CO} 2, \mathrm{H} 2 \mathrm{O}, \mathrm{NO} 2$ and $\mathrm{CH} 4$ efficiently absorb radiation in the infrared range, trapping the radiation reflected from the earth, causing the well-known "greenhouse effect". In contrast, aerosol particles are thought to have an overall cooling effect, estimated to be of the same order of magnitude as the positive forcing of greenhouse gases (IPCC, 2001). However, these estimates are still subject to wide uncertainties, mainly due to the fact that aerosol climate forcing depends on the optical properties and spatial distribution of the aerosols, both of which vary greatly according to the sources, location, and age of the aerosols. Aerosol particles both absorb and scatter light, with the efficiency of the processes being highly dependent on their size distribution, chemical composition and the wavelength of the incident radiation. Scattering efficiency is predominantly a function of particle size, morphology, and chemical composition, and is mainly due to aerosol particles in the accumulation range $(0.1-1 \mu \mathrm{m})$. The light absorption by aerosols covers the whole spectrum, and is largely due to near-graphitic carbon (also called elemental, or black carbon), whose unique known source are combustion processes.

Of the various major aerosol particle types, those emitted during biomass burning are amongst the most optically active

(C) European Geosciences Union 2003 
(Reid and Hobbs, 1998) due to the fact that they are predominantly in the form of submicrometer, accumulation-mode particles, and also contain a high content of light-absorbing components. This, coupled with the fact that biomass burning has been estimated to be the second largest source of anthropogenic aerosols (IPCC, 2001), has led to extensive investigation of smoke aerosols (both laboratory and field based), with a primary aim being to determine their contribution to Earth's radiation balance. Despite these efforts, however, the radiative forcing due to aerosol particles is still subject to large uncertainties (at least a factor of two), and the confidence level of global estimates is considered as "low" (Andreae and Crutzen, 1997; Shine and Forster, 1999; IPCC, 2001).

Biomass burning activities are most concentrated in the tropical areas of Africa, Indonesia and South America (Andreae, 1991), where fire is routinely used for both deforestation and seasonal burning of secondary forests and pastures. Of these regions, the Amazon basin has perhaps been the focus of most international attention, due to the fact that it contains the world's largest tropical rainforest and continues to experience one of the highest rates of deforestation in the world. Measurement campaigns like the Smoke, Cloud, Aerosol and Radiation-Brazil (SCAR-B) experiment (Kaufman et al., 1998) and the dry and wet season Amazon Boundary Layer Experiments (ABLE 2A and 2B) (Harriss et al., 1988; Harriss et al., 1990), have sought specifically to improve our understanding of the environmental and climatic effects of biomass burning and background aerosols in this region. As a result, it is now clear that smoke aerosols emitted in Amazonia have a very strong local impact on incoming radiation (Ross et al., 1998). Moreover, recent studies have shown that the smoke produced in the tropics may be subject to high altitude uplift and long-range transport due to the intense convective activity (Andreae, 1991; Pickering et al., 1996; Andreae et al., 2001; Staudt et al., 2001). The potential, therefore, exists for the extensive biomass burning in the Amazon basin to have a global influence (Andreae et al., 2002). Ongoing studies of the sources, properties and processes involving aerosols are therefore critical for this region.

The current study was carried out during the recent LBA-EUSTACH 1 and 2 campaigns (LBA = LargeScale Atmosphere-Biosphere Experiment in Amazonia; EUSTACH = European Studies of Trace Gases and Atmospheric Chemistry) (Nobre et al., 2001; Andreae et al., 2002), which formed part of the LBA project, a major international initiative designed to investigate the Amazon rainforest ecosystem, its links to the atmosphere and climate, as well as the significant impacts of human activities in the region. We focus here on a comparison of the physical properties of aerosols (number concentration, size distribution, scattering and absorption coefficients, single-scattering albedo, and aerosol optical depth) representative for background conditions (LBA-EUSTACH 1) with those for fresh and aged smoke from anthropogenic biomass burning (LBAEUSTACH 2). This study contributes towards a more thorough understanding of the regional and global climatic effects of widespread biomass burning in Amazonia and other tropical regions.

\section{Sampling location and methodology of measurements}

\subsection{Sampling location}

Aerosols were sampled during two field campaigns on a $54 \mathrm{~m}$ tower situated in a primary rainforest (Reserva Biologica Jarú, Rondônia, Brazil, $10^{\circ} 04^{\prime} 55^{\prime \prime} \mathrm{S}, 61^{\circ} 55^{\prime} 48^{\prime \prime} \mathrm{W}, 110 \mathrm{~m}$ above sea level), in April-May 1999 (LBA-EUSTACH 1) and September-October 1999 (LBA-EUSTACH 2). The LBA-EUSTACH 1 campaign covered the end of the wet season period and the transition period toward the biomassburning-influenced dry season. LBA-EUSTACH 2 was conducted throughout the end of the dry season and the transition period toward the wet season again. For a more complete description of the site and overall sampling conditions, refer to Andreae et al. (2002).

\subsection{Particle concentrations}

Aerosol particle concentrations in the size range $0.01-3-\mu \mathrm{m}$ diameter were measured with a condensation particle counter (CPC 3010 or 3762, TSI, USA). The instruments were fitted with a diffusion drier installed in front of the inlet, because direct sampling of the extremely humid ambient air would have led to condensation of water within the instrument. The diffusion dryer consisted of a cylindrical metal mesh (length $0.59 \mathrm{~m}$, diameter ca. $13 \mathrm{~mm}$ ) surrounded by a plastic tube filled with silicagel. The losses due to the inlet tubing and the diffusion drier were determined to be ca. $19 \%$, for which the measurements were corrected. In addition, the raw data were adjusted for coincidence losses by applying an algorithm recommended by the manufacturer. On a few occasions $(<0.3 \%$ of total measurement time) during the LBAEUSTACH 2 campaign (always at night), the CPC instrument was saturated when smoke plumes passed over the site.

\subsection{Size distributions}

Continuous particle number/size distributions were measured using a passive cavity aerosol spectrometer probe, the PCASP-100x (PCASP, DMT, USA, now owned by Particle Metrics, Longmont, USA), with a one-minute time resolution. The PCASP measured particle size distribution from diameters ranging $0.1-3 \mu \mathrm{m}$ in 18 channels, derived from the light scattering properties of the particles at a wavelength of $633 \mathrm{~nm}$ between angles of $35^{\circ}$ and $135^{\circ}$. The instrument was calibrated by the manufacturer, using polystyrene latex particles of known size. The refractive index of latex beads (1.59 
$-0 i$ ) is different from that of atmospheric particles, resulting in a size distribution that is "latex equivalent". Guyon et al. (2003) have shown that the refractive index of ambient aerosol particles may be subject to large intra- and interday variations, as a function of aerosol sources, age, and relative humidity (RH). Here, we are presenting PCASP size distributions corrected for an average refractive index calculated for three periods of interest. The three periods were designated as follows: (1) LBA-EUSTACH 1, before the transition period (representative for background, wet season conditions), (2) LBA-EUSTACH 1, during the transition period toward the biomass-burning-influenced, dry season period, and (3) LBA-EUSTACH 2, largely dominated by biomass burning conditions. The average refractive indices associated with each period were $1.42( \pm 0.04)-0.006( \pm 0.003) i$, $1.46( \pm 0.06)-0.016( \pm 0.003) i$, and $1.41( \pm 0.05)-0.013$ $( \pm 0.005) i$, respectively. Refractive indices were obtained for near-ambient conditions of temperature and relative humidity using Mie scattering theory in combination with a new iterative process, which utilizes the raw PCASP-measured size distributions and independently measured scattering and absorption data as inputs (Guyon et al., 2003). To facilitate comparison of the size distributions observed during the different periods studied, the distributions were normalized by the concentration of the size bin of the PCASP showing the largest value in the accumulation mode (0.1-1 $\mu$ m diameter).

Mass/size distributions were obtained from a microorifice uniform deposit impactor (MOUDI, model 110, MSP corporation, Minneapolis, USA) (Marple et al., 1991). For a complete description of the instrument and the sampling procedure, refer to Guyon (2002) and Guyon et al. (2003). Mass concentrations were obtained by gravimetric analysis. The aluminum substrates were weighed before and after sampling, with a Mettler microbalance ( $1 \mu \mathrm{g}$ sensitivity), after having been left equilibrating under controlled conditions of $\mathrm{RH}(50 \%)$ and temperature $\left(20^{\circ} \mathrm{C}\right)$ for at least 24 hours. The accuracy of the measurements is ca. $\pm 3 \mu \mathrm{g}$. The MOUDI mass/size distributions were inverted following the work of Roberts et al. (2002), which is an adaptation of the Twomey nonlinear iterative algorithm described by Winklmayr et al. (1990). Collection efficiencies $E(D)$ for our MOUDI were obtained by calculating the steepness factor s associated with each MOUDI stage from the collection efficiencies reported by Marple et al. (1991), using

$E(D)=\left[1+\left(\frac{D_{50}}{D}\right)^{2 s}\right]^{-1}$

with $D$ the particle diameter, and $D_{50}$ the $50 \%$ cutoff diameter, and fitting the $E(D)$ s-shaped function to the $D_{50}$ characteristic for our instrument. This procedure allowed us to retrieve continuous size distributions, which contain more information than the histogram obtained from directly plotting the mass concentration measured for each MOUDI stage.
Uni- and bimodal number, volume, and mass/size distribution were parameterized by a lognormal equation:

$\frac{d Q}{d \log D}=\sum_{i=1}^{2} \frac{Q_{i}}{\sqrt{2 \pi} \sigma_{i}} \exp \left[-\frac{\left(\ln D-\ln D_{Q, i}\right)^{2}}{2 \sigma_{i}^{2}}\right]$

where $Q$ expresses the number, volume or mass quantity, $D_{Q, i}$ is the median particle diameter of the mode $i$ for the quantity $Q$, and $\sigma_{i}$ is the standard deviation.

\subsection{Scattering coefficients}

Light-scattering measurements were made with a singlewavelength $(\lambda=545 \mathrm{~nm})$ nephelometer (model M903, Radiance Research, Seattle, USA). Aerosols were sampled continuously and the data averaged and collected on a oneminute time resolution. No attempt was made to dry the particles prior to sampling. Nevertheless, the internal heat produced by the instrument itself may have partially dried out the sampled particles. On average, the RH inside the instrument was $15 \%( \pm 6 \%)$ lower than ambient RH.

The Radiance Research nephelometer measures light scattering between $8.9^{\circ}$ and $170^{\circ}$ angles, so that the scattering coefficients retrieved from the instrument are truncated for the very forward and backward scattering angles, and therefore are lower than the effective total scattering from the sampled particle population. Anderson et al. (1996) proposed a method for correcting scattering measurements obtained from a three-wavelength TSI 3563 nephelometer (an instrument with similar characteristics to ours), based on the Ångström exponent derived from the scattering values obtained at 450 and $700 \mathrm{~nm}$. They found that this instrument underestimates the total scattering coefficients by up to $10 \%$ for submicrometer particles, and $20-50 \%$ for supermicrometer particles. This correction procedure could not be employed for our instrument, since it measures at only a single wavelength. However, such a correction factor could be retrieved as a "by-product" of an iterative procedure we recently developed for estimating the refractive index of atmospheric aerosols (Guyon et al., 2003). In this procedure, hourly averages of scattering coefficients, absorption coefficients and PCASP number size distributions from both measurement campaigns were used concomitantly in combination with a standard Mie scattering model, so that absorption and scattering coefficients could be recalculated from the size distribution of the PCASP. The angular truncation of the nephelometer was taken into account in the Mie program, and the corrected scattering coefficient $\left(\sigma_{s}\right)$, as well as the truncated scattering coefficients $\left(\sigma_{s, \text { trunc }}\right)$ (identical to the one measured by the nephelometer), were retrieved. From these, a correction factor, $F_{\text {trunc }}\left(=\sigma_{s} / \sigma_{s, \text { trunc }}\right)$, could be extracted and applied to the whole data set, as explained in detail in Sect. 3.4. The errors associated with the scattering values presented herein are therefore considered to be due only to measurement error of the instrument itself (ca. 5\%). 


\subsection{Absorption coefficients}

Continuous absorption coefficient measurements were made using a Radiance Research particle soot absorption photometer (PSAP). The PSAP operates using the principle of an integrating plate, measuring transmittance through a glass fiber filter at a wavelength of $565 \mathrm{~nm}$. Values were collected every 5 minutes during the LBA-EUSTACH 1 campaign and every minute during LBA-EUSTACH 2, due to high aerosol loading resulting from local biomass burning. Absorption coefficients, $\sigma_{a}$, were retrieved according to Bond et al. (1999) for PSAP filter transmittance $>0.5$. Uncertainties were computed following the work of Anderson et al. (1999). For a complete description of the data handling and uncertainties associated with the PSAP instrument, refer to Guyon (2002) and Guyon et al. (2003).

\subsection{Aerosol optical depth}

Aerosol optical depth (AOD, $\tau$ ) under cloud-free atmospheric conditions was measured during both measurement campaigns using a Yankee multifilter rotating shadowband radiometer (MFR) (MFRSR-7, Yankee Environmental Systems, Turner Falls, USA) (Harrison et al., 1994). In the present study, five wavelengths were used $(415,500,615$, 671, and $867 \mathrm{~nm}$ ). First, the Langley technique was applied on morning and afternoon data of air masses, $m$, ranging between 2 and 6 , in order to acquire an estimate of the solar constant from the intercept of the regression line of the measured irradiance on the air masses (Harrison and Michalsky, 1994). A set of clear days was chosen from each period to obtain the value of the solar constant for each wavelength and then the Beer-Lambert-Bouguer law was applied to derive instantaneous measurements of the total optical depth (one-minute time resolution). The AODs for the five wavelengths were then obtained by subtracting the contribution of Rayleigh scattering and ozone absorption from the total optical depth. A more detailed description of the instrumentation, methodology, and quality control can be found in Formenti et al. (2000) and references therein.

\section{Results and discussion}

\subsection{Aerosol particle concentration}

During both the LBA-EUSTACH 1 and the LBA-EUSTACH 2 campaigns, two CPC instruments were used to acquire total aerosol particle concentration data for particles in the size range of 0.01-3.0 $\mu \mathrm{m}$ diameter (Fig. 1).

The low concentrations (median of ca. $400 \mathrm{~cm}^{-3}$ ) measured at the beginning of the first campaign (April) compare to those found for marine air, which typically exhibits particle concentrations of $100-300 \mathrm{~cm}^{-3}$ (Fitzgerald, 1991; Finlayson-Pitts and Pitts, 2000; Raes et al., 2000). Given that the removal of fine mode aerosols from the troposphere

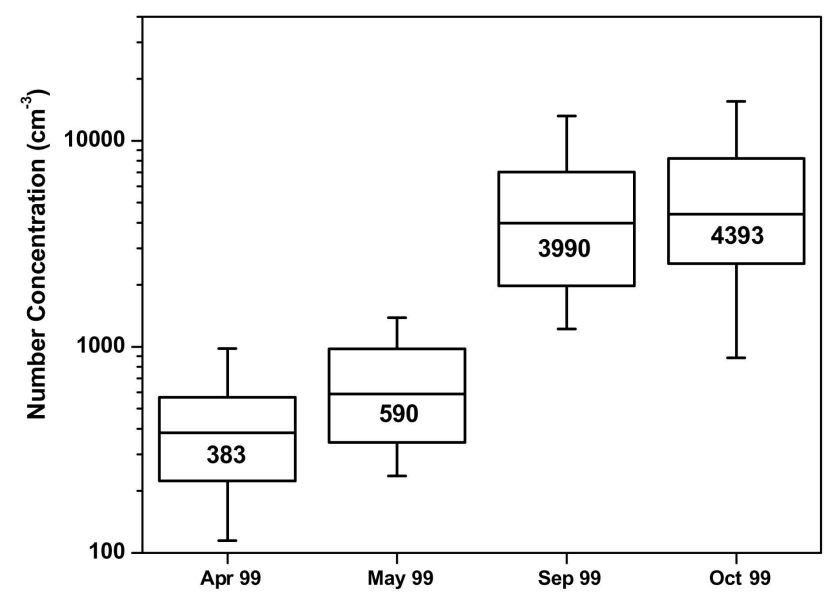

Fig. 1. Aerosol particle concentrations (diameter $>10 \mathrm{~nm}$ ) during the wet-to-dry season transition (LBA-EUSTACH 1, AprilMay) and the dry-to-wet season transition (LBA-EUSTACH 2, September-October). The horizontal bars and the corresponding values inside the boxes represent the median concentrations, while the box defines the first and third quartiles, and the vertical bars the 5th and 95th percentiles.

is usually largely due to the incorporation of the aerosols into cloud droplets, followed by precipitation, as well as to scavenging below clouds during rain (Finlayson-Pitts and Pitts, 2000), these remarkably low concentrations are undoubtedly associated with the large amount of precipitation observed during the month of April (Andreae et al., 2002), as well as with the weak sources of aerosol particles in the Amazon basin during the non-burning season (Artaxo and Hansson, 1995). Similar concentrations were observed by (Roberts et al., 2001) and (Zhou et al., 2002) in the Amazonian site of Balbina, north of Manaus, in 1998 (average particle concentrations of $460 \pm 320 \mathrm{~cm}^{-3}$ ), suggesting that conditions encountered in the unpolluted Amazon basin resemble more those observed from marine environments in contrast to what is typically reported for continental environments (Williams et al., 2002).

Precipitation decreased during the month of May, and particle concentrations consequently increased (median of ca. $600 \mathrm{~cm}^{-3}$, Fig. 1), indicating a transition from the wet season toward the dry season (Andreae et al., 2002). This increase in particle concentration also coincided with the onset of fire activity in the states neighboring Rondônia (RO), principally in the states of Mato Grosso do Sul (MS), Mato Grosso (MT), Goiás (GO), and Pará (PA), as detected by the NOAA-12 satellite (Fig. 2) (also available from CPTEC at http://www.cptec.inpe.br/products/queimadas/).

It is noteworthy that there were actually no fire pixels detected in the state of Rondônia, where the measurements took place, and virtually none north of the tower (state of Amazonas (AM)), over the two months 
covering the LBA-EUSTACH 1 campaign (Fig. 2). However, five-day back trajectories calculated for a starting altitude of $500 \mathrm{~m}$ using the NOAA/Air Resources Laboratory HYbrid Single-Particle Lagrangian Integrated Trajectory (HYSPLIT4) model (Draxler and Hess, 1998) clearly show that air masses passing over the sampling site during this period were all coming from those areas that contributed to most of the fire activity in the region, namely MT, MS, and GO states. According to the back trajectories (Fig. 3), these biomassburning-influenced air masses required some 2-3 days to reach the sampling site. In light of this, we consider the beginning of the LBA-EUSTACH 1 campaign (08 April12 May 1999) to be representative for background Amazonian conditions, whilst the second part of the campaign (1321 May 1999) was influenced by aged smoke from biomass burning. We also note here that local anthropogenic activity is not believed to have contributed significantly to the observed changes in the aerosol properties. The measurement site was located in a remote region and the area surrounding it was largely devoid of human activity. During the wet season the site could only be accessed by boat, some 5 hours journey from the town of Ji-Paranà, which is situated south of the site. Some new farming activity was occurring west of the measurement site, but the dirt road serving the few settlers living there was impassable at this time of the year. Wood is mostly used for cooking in the region, but this signature would be expected to form part of the background aerosol (if perceivable at all at our site), since there is no reason for an increase in cooking fuel consumption at this time of the year. The same is valid for our diesel generator, which was situated on a raft on the river, ca. $400 \mathrm{~m}$ from the tower, with the exhaust directed just above the water level.

The burning season in Rondônia reached its peak during the month of September, when the LBA-EUSTACH 2 campaign started. This was a month later than for its neighboring state to the East, MT, where the most intense biomass burning activity for the year 1999 occurred in Brazil (Fig. 2). During the burning season, most of the biomass burning spots in Amazonia occur in the transition between savanna and forest, mostly in the states of MT, MS, RO, GO, PA, and Tocantins. This burning activity had a dramatic effect on the measured aerosol particle concentrations. The total amount of particles increased by an order of magnitude compared to the LBA-EUSTACH 1 campaign, with the median number concentration exceeding $4000 \mathrm{~cm}^{-3}$. This is clear evidence of the strong impact that human activities are having on the atmospheric conditions over the Amazon region.

The measured aerosol concentrations in Rondônia decreased significantly in the last week of October (median of ca. $1700 \mathrm{~cm}^{-3}$, compared to an overall median of ca. $4400 \mathrm{~cm}^{-3}$ ). During this week, rainfall frequency increased, signaling the transition towards the next wet season.

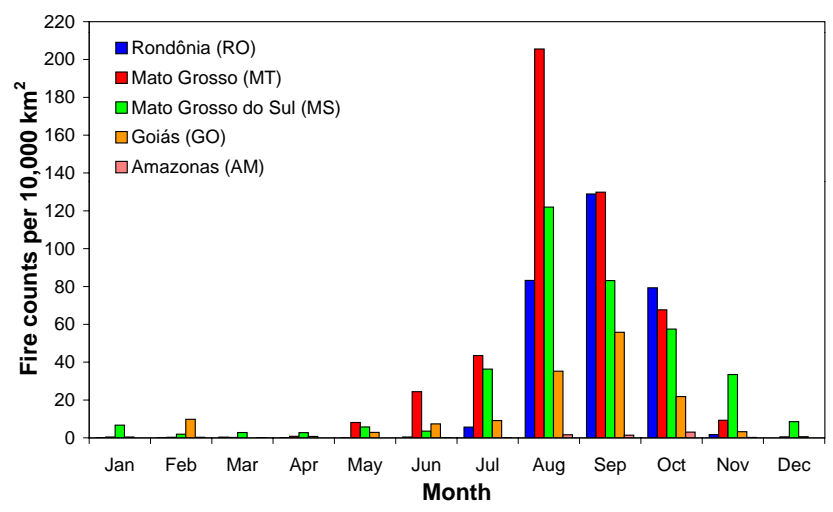

Fig. 2. Monthly fire activity detected by the AVHRR-NOAA-12 satellite over the Amazon basin for the states of Rondônia (RO), Mato Grosso (MT), Mato Grosso do Sul (MS), Goiás (GO), and Amazonas (AM) in 1999. The data presented are the total number of fire pixels per $10000 \mathrm{~km}^{2}$ detected over the Brazilian states.

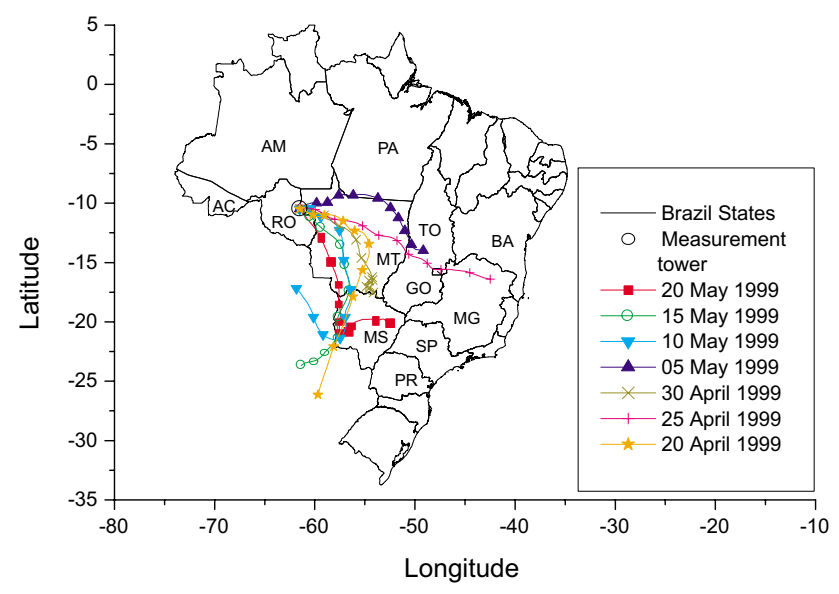

Fig. 3. Representative five-day (HYSPLIT-4) back trajectories calculated for the LBA-EUSTACH 1 campaign. The starting point was the measurement tower $\left(10^{\circ} 05^{\prime} \mathrm{S}, 61^{\circ} 56^{\prime} \mathrm{W}\right)$, for an altitude of $500 \mathrm{~m}$ above ground level. The symbols are spaced at 12-hour intervals along the trajectories.

\subsection{Aerosol optical depth (AOD)}

Daily AOD (at $500 \mathrm{~nm}$ - unless otherwise stipulated, this wavelength will be henceforth used as reference) and Ångström exponents (estimated from AOD values obtained at 868 and $416 \mathrm{~nm}$ ) derived from the 1-minute time resolution MFR measurements are presented for both field campaigns in Fig. 4. The number of data points retrieved was mainly restricted by the large number of cloudy days observed during both field campaigns. For the same reason, some of the averages presented were obtained for shorter periods than over the whole day (excluding values at high air masses, $m>6$ ).

AOD showed very little diurnal variability, especially during the LBA-EUSTACH 1 campaign, so that even a few 
hours of measurements can be an acceptable estimate of the daily average. However, morning values were generally higher than the daily average, as were the scattering coefficients (Sect. 3.4), which may be attributed to the high relative humidity observed in the mornings.

The same overall temporal trend was observed in AOD values as for the other aerosol data measured during the LBA-EUSTACH 1 campaign. Background AOD values (period preceding 12 May 1999) were centered at 0.048 (first and third quartile of 0.040 and 0.056 , respectively), which is only about twice the estimated detection limit for the instrument (Formenti et al., 2000). These values are in the lower range (0.038-1.41) of values given by Horvath (1998) for clean continental conditions at $500 \mathrm{~nm}$, and about half those measured by Formenti et al. (2001) in Balbina during nondusty days. AOD then progressively increased, reaching a value of 0.12 on 22 May.

The biomass-burning season (LBA-EUSTACH 2) was characterized by large day-to-day fluctuations in AOD, ranging from 0.1 to 2.0 , with a median value (first; third quartile) of $0.79(0.53 ; 1.02)$. These values are in the range of what has been measured at the pasture site during the same period by the AERONET (Holben et al., 1998) sunphotometer network (average of 0.91, standard deviation of 0.56 , and maximum of 3.3, at $500 \mathrm{~nm}$ ) (Artaxo et al., 2002). This highlights the regional influence of biomass burning, since the results appear to show that the atmosphere above the remote forest site, at which we measured, was influenced by biomass burning aerosols to about the same extent as that over the pasture site. Other authors, such as Dubovik et al. (2002), also reported AOD values (at $440 \mathrm{~nm}$ ) ranging from 0.1-3.0 (0.74 on average) for biomass burning-influenced periods in 1993 and 1994 over the Brazilian Amazonian forest, and in 1998 and 1999 over the Bolivian Amazonian forest. The range of AODs obtained for this season is of the same magnitude as those reported by Horvath (1998) for polluted urban environments at $500 \mathrm{~nm}(0.4-4.36)$. The large range of values reported in these data sets, however, indicates the danger associated with using a single average AOD value to represent biomass burning haze in order to retrieve aerosol radiative forcing estimates.

AOD values at $550 \mathrm{~nm}$ were interpolated using the Ångström exponents obtained from the values for the neighboring wavelengths $(500$ and $616 \mathrm{~nm}$ ), and were regressed against the corresponding extinction coefficients obtained at ambient RH $<92 \%$ (the sum of the scattering and absorption coefficients at $550 \mathrm{~nm}$ presented in Sects. 3.4 and 3.5, respectively). The slope of the fitting equation provides an estimate of the scale height of the optically-active aerosol layer if it is assumed that the aerosols are well-mixed within the layer (assuming the pressure in this layer to be constant and equal to the surface pressure). Regression of the 10 minuteaveraged values yielded a layer height of ca. $4.5 \mathrm{~km}$ for the period preceding 12 May ( $r^{2}=0.93,51$ observations). This is much higher than the value of $1 \mathrm{~km}$ reported by Jacob

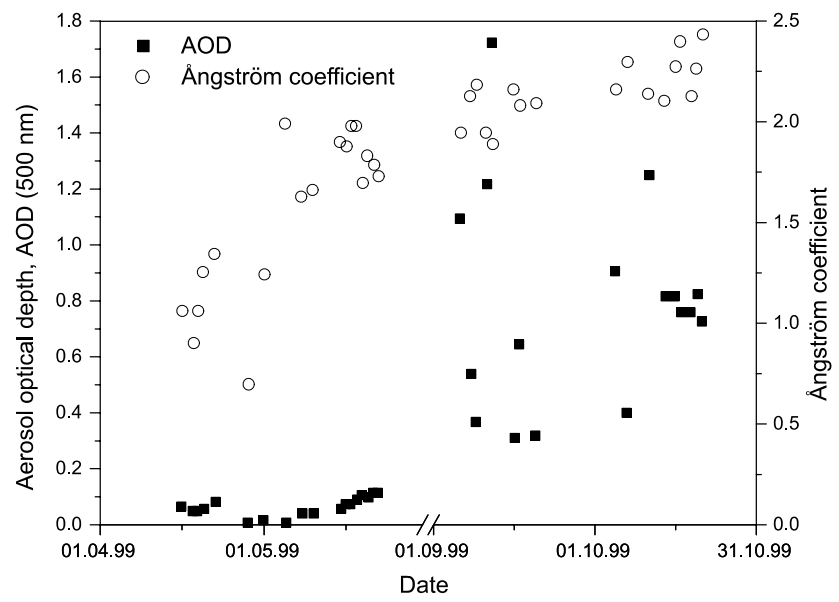

Fig. 4. Daily averages of the aerosol optical depth (AOD) observed at $500 \mathrm{~nm}$ (black squares), and the Ångström exponents (open circles) estimated from AOD values obtained at 868 and $416 \mathrm{~nm}$, with the MFR instrument. Data obtained for both the LBA-EUSTACH 1 and 2 campaigns are presented.

and Wofsy (1988) and Fisch et al. (2003) for the convective boundary layer (CBL) height at this site, or the value of ca. $2.0 \mathrm{~km}$ for the planetary boundary layer (PBL) given by Jacob and Wofsy (1990) for late-morning hours in the Amazon basin during the wet season. These authors found the PBL to be well mixed with the underlying sublayers, but fairly decoupled from the layer above. This indicates that the aerosols measured in situ on the tower during this period were probably not characteristic of the whole column, and that there was a significant contribution by free tropospheric aerosols to the (very low) AOD during this period.

Regression of the data for the 12-21 May period suggested a much shallower optically-active aerosol layer, ca. $1.1 \mathrm{~km}$ in depth $\left(r^{2}=0.44,154\right.$ observations). The lower regression coefficient obtained for the period 12-21 May reflects the fact that this period actually lies within the transition between the wet and dry seasons, during which an increase in all the measured aerosol optical parameters occurred. This period may therefore not be best described by a linear regression. However, as discussed in more detail in the single-scattering albedo section (Sect. 3.6), this reflects how biomass burning aerosol particles, even in relatively low amounts, can dominate the overall aerosol optical properties of the whole column when mixed in with background aerosol in remote areas.

The overriding influence of the smoke aerosol is also seen in the Ångström exponent data retrieved for the LBAEUSTACH 1 campaign (Fig. 4). Ångström exponents showed a dramatic increase from the beginning to the end of the first campaign, and then to the dry season campaign: values increased from below unity to over 2 (Fig. 4). Ångström exponent values of ca. 2 are typical for small smoke particles, whereas values tending toward zero are representative of large particles (e.g., dust) (Dubovik et al., 2002). This attests 

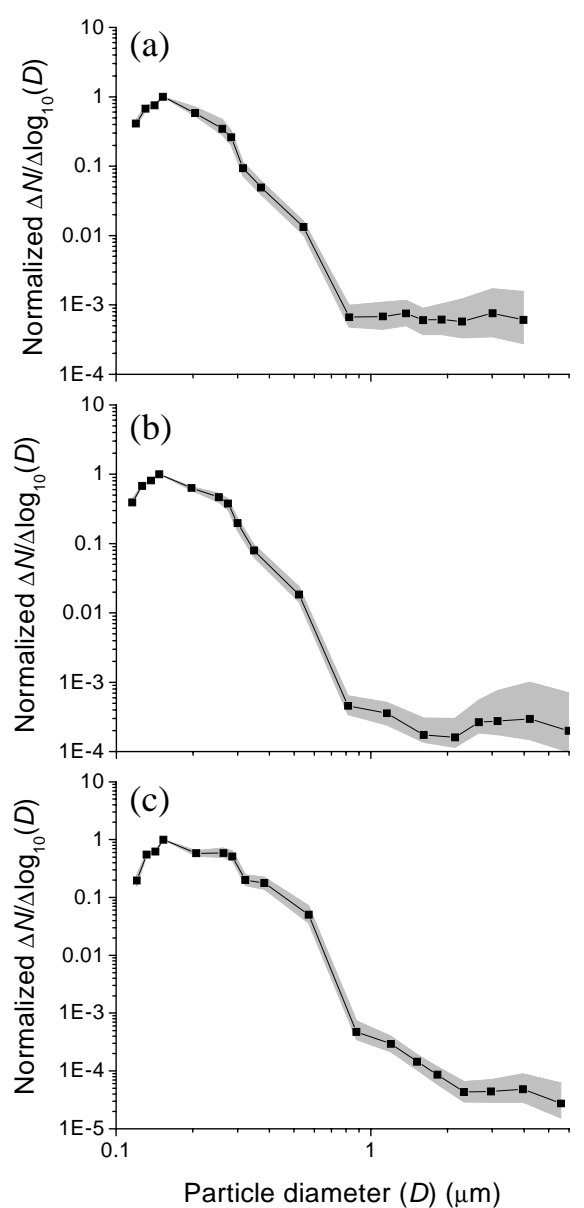
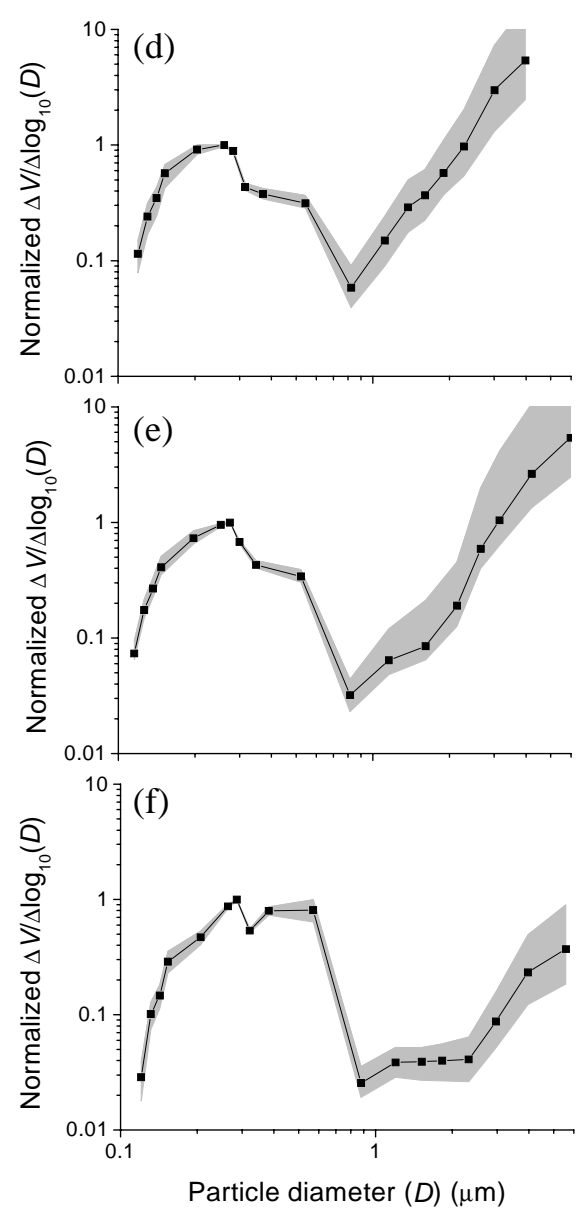

Fig. 5. Normalized number size distribution for (a) background aerosols, (b) background aerosols altered by an aged biomass smoke, (c) and regional biomass burning haze measured over the Amazonian rain forest in Brazil during the LBA-EUSTACH campaigns. In each case, the solid line represents the median size (diameter) distribution obtained over the considered period. The gray zone is the area between the first and the third quartile size distribution for each period. Figures $\mathrm{d}-\mathrm{f}$ show the same as a-c but for normalized volume/size distributions.

to the growing contribution of fine particles to the opticallyactive aerosol loading with increasing biomass burning activity, whereas background aerosols seem to be characterized by a prevailing coarse mode. The increase in Ångström exponents is particularly noticeable between the beginning and the end of the LBA-EUSTACH 1 campaign, indicating a radical change in the make-up of the optically-active aerosol layer. This is consistent with the shift from a prominent biogenic coarse-mode aerosol prevailing over the unpolluted Amazon to conditions dominated by biomass smoke during the dry season (Artaxo et al., 2002).

\subsection{Number, volume, and mass size distributions}

The mean normalized number size distributions $\left(\Delta N / \Delta \log _{10}(D)\right)$ measured by the PCASP for pristine background conditions (period preceding 12 May), background conditions affected by aged biomass smoke (period 12-21 May), as well as for regional biomass burning haze (LBA-EUSTACH 2 campaign), are presented in Figs. 5a-c. In each case, the accumulation mode (particles of $D<1 \mu \mathrm{m}$ ) of the size distribution could be fitted by a lognormal equation $\left(r^{2}>0.86\right)$, yielding the geometric mean diameter and geometric standard deviation parameters summarized in the first column of Table 1.

The overall shape of the normalized number distributions did not vary significantly from the beginning (Fig. 5a) to the end of the LBA-EUSTACH 1 (Fig. 5b) campaign, although absolute concentrations increased significantly (Sect. 3.1). Both median number distributions show a similar bimodal profile with maxima at ca. 0.17 and 3-4 $\mu \mathrm{m}$ for the accumulation and coarse modes, respectively. The standard deviations for the two distributions are also quite similar, with a slightly broader distribution in the second period (especially for particles with diameters of ca. $0.2-0.3 \mu \mathrm{m}$ ). The coarse mode could not be successfully fitted to a lognormal curve because of its relatively low abundance and because of interference by a smaller intermediate mode at ca. $0.8-$ 
Table 1. Particle size parameters (mean \pm standard error for the lognormal fitting equation) for Amazonian aerosols observed during the LBA-EUSTACH 1 and 2 campaigns

\begin{tabular}{|c|c|c|c|c|c|c|}
\hline & \multicolumn{2}{|c|}{ Particle number distribution } & \multicolumn{2}{|c|}{ Particle volume distribution } & \multicolumn{2}{|c|}{ Particle mass distribution } \\
\hline & Mean diameter $(\mu \mathrm{m})$ & Standard deviation & Mean diameter $(\mu \mathrm{m})$ & Standard deviation & Mean diameter $(\mu \mathrm{m})$ & Standard deviation \\
\hline 6-12 May $1999^{1}$ & $0.17 \pm 0.003$ & $0.30 \pm 0.03$ & $\begin{array}{c}0.23 \pm 0.008 \\
6.86 \pm 2.04\end{array}$ & $\begin{array}{l}0.33 \pm 0.04 \\
0.55 \pm 0.10\end{array}$ & $\begin{array}{l}0.35 \pm 0.01 \\
3.77 \pm 0.04\end{array}$ & $\begin{array}{l}0.36 \pm 0.01 \\
0.41 \pm 0.01\end{array}$ \\
\hline $13-21$ May $1999^{2}$ & $0.17 \pm 0.004$ & $0.34 \pm 0.03$ & $\begin{array}{c}0.24 \pm 0.008 \\
9.39 \pm 1.68\end{array}$ & $\begin{array}{l}0.37 \pm 0.03 \\
0.55 \pm 0.07\end{array}$ & $\begin{array}{l}0.34 \pm 0.01 \\
2.78 \pm 0.10\end{array}$ & $\begin{array}{l}0.32 \pm 0.01 \\
0.87 \pm 0.04\end{array}$ \\
\hline Sep-Oct $1999^{3}$ & $0.19 \pm 0.007$ & $0.36 \pm 0.05$ & $\begin{array}{l}0.36 \pm 0.03 \\
6.65 \pm 10.1\end{array}$ & $\begin{array}{c}0.52 \pm 0.06 \\
0.49 \pm 0.8\end{array}$ & $0.41 \pm 0.02$ & $0.46 \pm 0.01$ \\
\hline
\end{tabular}

${ }^{1}$ MOUDI samples taken from 6 April to 14 May $1999,{ }^{2}$ from 14 to 21 May 1999, and ${ }^{3}$ on 5-6 October 1999

$1.5 \mu \mathrm{m}$. For the whole of the LBA-EUSTACH 1 campaign, the relative concentration ratios for the size bins within the accumulation mode varied from the median values by less than a factor of 1.5 for $75 \%$ of the time, whereas they varied by up to a factor of ca. 3 for the coarse and intermediate modes. This higher variability for the larger particle sizes could be due to the poorer counting statistics in this range (Le Canut et al., 1996).

Compared to the distributions observed for the LBAEUSTACH 1 campaign, the dry-season number/size distribution (Fig. 5c) shows a broader accumulation mode and a greater abundance of accumulation mode particles relative to coarse mode particles. This is due to the fact that biomass burning contributes mostly to the release of accumulation mode particles into the atmosphere. This mode, which shows a number median diameter centered at ca. $0.19 \mu \mathrm{m}$, is similar in shape to that measured by Reid et al. (1998) for local haze in Cuiabá (using a PCASP instrument and assuming a particle refractive index value of $1.50-0.02 i)$. The accumulation mode seems to be composed of two sub-modes a dominating mode at ca. $0.15 \mu \mathrm{m}$ (comparable to the other distributions), and a second one at ca. $0.3 \mu \mathrm{m}$. Similar to our observations, Reid et al. (1998) and Le Canut et al. (1996) also found two modes with maxima at particle diameters of ca. $0.1-0.18 \mu \mathrm{m}$ and ca. $0.2-0.3 \mu \mathrm{m}$ in the number size distribution of "background aged biomass-burning smoke", using a similar instrumentation to ours. Bimodal size distributions of submicron smoke aerosol particles from mobility analyzers have also been published previously, with the first mode typically peaking at particles diameter $<0.1 \mu \mathrm{m}$, i.e. smaller than what was observed in the present study (for a recent publication, see for example Hedberg et al., 2002). The second mode within the accumulation mode could be attributed to condensational growth and/or coagulation as the particles aged. Radke et al. (1995) observed growth of forest fire particles from the emitted Aitken mode $(D<0.2 \mu \mathrm{m})$ to accumulation mode sizes $(D=0.2-2 \mu \mathrm{m})$ within the first few hours after emission. Assuming, in our case, a mix- ture of aged and younger smoke particles would be consistent with our observations of the presence of concentrated regional haze disturbed occasionally by more local younger plumes. However, these two modes are typically observed from PCASP data as, for example, Reid and Hobbs (1998) did not observe such a pattern in their differential mobility particle sizer data, and we cannot exclude that this could not be a product of some artifact in the PCASP data.

It can be seen from Figs. 5a-c that the number size distributions obtained from the PCASP instrument are truncated for particles smaller than $0.1 \mu \mathrm{m}$, and that this lower cutoff diameter occurs near the maxima observed for the accumulation modes. A consequence of this is that during the LBAEUSTACH 2 campaign, the PCASP could only account for ca. $60 \%$ of the total number of particles detected by the CPC. The unaccounted-for fraction consists predominantly of particles of the Aitken mode emitted during the fires. Although very numerous, these fine particles contribute little to the total aerosol mass and volume, and are characterized by very small scattering and absorption cross sections due to their small size.

The normalized volume distributions $\left(\Delta V / \Delta \log _{10}(D)\right)$ for the three periods defined above are shown in Figs. 5df. It can be seen that the PCASP accounts for most of the accumulation mode volume, but truncates the coarse mode. All three distributions appear to have a bimodal accumulation mode, which could be due to an artifact of the instrument, as described above. However, examination of the raw data showed that the PCASP correction for the refractive index is not a primary source of error, but emphasizes the irregularities already existing in the distribution. Therefore, and despite the resulting poor fit $\left(r^{2}\right.$ of 0.87 for the dry season data, but fitting poorly the central size bins at $D=0.2$ $0.6 \mu \mathrm{m}$ ), we decided to apply a unique lognormal equation to the accumulation mode of these curves, which has probably a more physical meaning. We note here that it cannot be excluded that the accumulation mode might actually be bimodal in nature for the dry season distribution; however, 


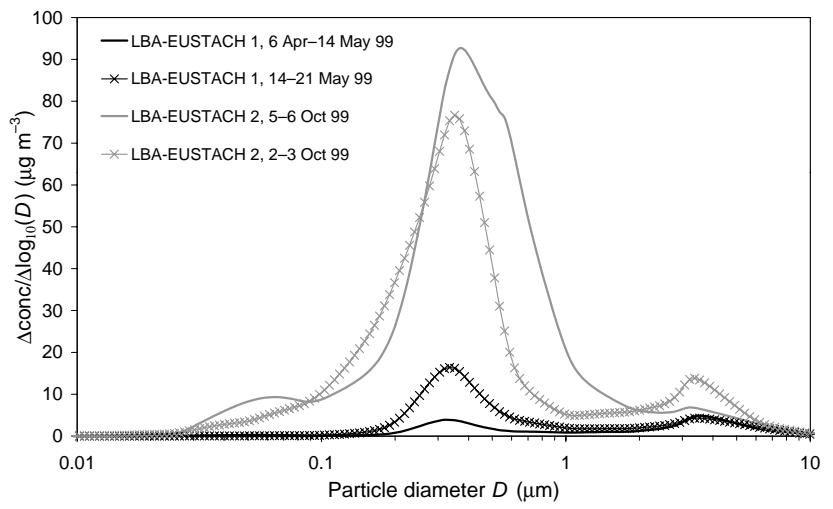

Fig. 6. Typical MOUDI mass size distributions for background aerosol (black line, 6 April-14 May 1999), background aerosol under increasing influence of biomass burning (linked black crosses, 14-21 May 1999), concentrated biomass burning aerosol (gray line, 5-6 October 1999), and young biomass burning plume (linked gray crosses, 2-3 October 1999) measured in the Amazon basin during the LBA-EUSTACH campaigns. The background size distribution is an average distribution from six three-day MOUDI samples, whilst the biomass burning-influenced background distribution is an average of two three-day samples.

the two peaks are too sharp in shape, and overlap too much to be successfully fitted individually by lognormal equations.

The parameters describing the best fit of lognormal equations to the volume distributions are summarized in the second column of Table 1. The standard errors associated with the lognormal parameterization of the coarse mode are large because of the upper truncation of this mode. Guyon et al. (2003) reported that the correction for the refractive index applied to the PCASP data might overestimate the sizes of the particles in the coarse mode, because a constant refractive index is assumed over the whole size distribution, and the absorption in this mode might be overestimated. The volume mean diameter for the accumulation mode increases with increasing amounts of haze aerosols, from ca. $0.23 \mu \mathrm{m}$ during the wet season to ca. $0.36 \mu \mathrm{m}$ for the smoke haze period. Reid et al. (1998) reported values in the range 0.25$0.30( \pm 0.02) \mu \mathrm{m}$ for regional haze using the same instrument (see above). The same authors also reported a mean volume diameter of $0.28-0.35( \pm 0.05) \mu \mathrm{m}$, obtained using a differential mobility particle sizer. Dubovik et al. (2002) reported an AOD-dependent mean volume radius of $0.14+$ $0.013 \times \mathrm{AOD}$ (at $440 \mathrm{~nm}$ ), and a geometric standard deviation of $0.40 \pm 0.04$ for aerosols emitted by biomass burning in the Amazon. Applying a central AOD of ca. 0.9 at $440 \mathrm{~nm}$ (Sect. 3.2) to this equation would yield a mean volume diameter of ca. $0.30 \mu \mathrm{m}$. The latter value, derived from ground-base radiometer measurements, is slightly lower than those found in the current study, but confirms the observed trend of increasing accumulation mode mean volume diameter with increasing burning activity.
Typical mass size distributions (obtained as described Sect. 2.3) for the three periods are shown in Fig. 6, and the lognormal fit parameters associated with each distribution are summarized in the third column of Table 1. The discrepancy in geometric standard deviation observed between the number, volume, and mass/size distributions of each period is an indication of the overall uncertainty associated with these distributions, as the standard deviation of a distribution should remain the same for all distribution types (Hinds, 1999). In most cases, the lognormal fit of the regional haze coarse mode (5-6 Oct. 1999) was difficult, if not impossible to apply, due to the overlap of this mode with the large accumulation mode. However, the profile of the coarse mode during this period was generally similar to that found under background conditions, although slightly higher concentrations were observed. As was the case for the PCASP data, a second peak is noticeable within the regional haze accumulation mode at $D \sim 0.55 \mu \mathrm{m}$. However, this peak is less pronounced in the MOUDI compared to the PCASP data, and the MOUDI distribution is narrower than the PCASP volume distribution, which could be due to overcorrection of the PCASP data or in inverting the MOUDI data. A peak in fine particles could also be observed at $0.05-0.07 \mu \mathrm{m}$.

We note here that on some occasions, MOUDI samples were obtained with the dominant fraction collected one stage lower than usual (stage 8 , of aerodynamic cut-off $D_{50}=$ $0.200 \mu \mathrm{m}$, instead of stage $7, D_{50}=0.346 \mu \mathrm{m}$ ). One of these samples (2-3 Oct 1999) was identified as a young biomassburning plume (Guyon et al., 2003), and the lognormal fit yielded mean diameters (standard deviations) of $0.31 \pm 0.01$ $(0.50 \pm 0.05)$ and $3.15 \pm 0.16(0.46 \pm 0.01) \mu \mathrm{m}$ for the fine and coarse mode, respectively. Characteristically, this sample did not exhibit a second peak within the accumulation mode at larger diameter, suggesting that the presence of this peak in the regional haze samples could be attributed to condensational growth.

Figure 7 shows a scatter plot of the MOUDI mass concentrations measured during the LBA-EUSTACH 2 campaign against the corresponding integrated volume concentrations, for particles with diameters of $0.1-1 \mu \mathrm{m}$. Plotted are both volume concentrations derived directly from the "raw" PCASP size distributions, as well as the ones derived after adjustment of the PCASP size bins for the refractive index of the sampled aerosol. For this adjustment procedure we used the average refractive index value of $1.41-0.013 i$ calculated by Guyon et al. (2003) for biomass burning aerosols during this campaign. The regression analysis (with intercept forced to zero - the intercept being small and meaningless in our case, and insignificantly changing the $r^{2}$ of the regression) yielded an accumulation mode particle density of $1.38 \mathrm{~g} \mathrm{~cm}^{-3}$ (standard error of $0.03, r^{2}=0.95$ ) using the uncorrected PCASP data, and $0.65 \mathrm{~g} \mathrm{~cm}^{-3}$ (standard error of $0.01, r^{2}=0.94$ ) using the refractive index-adjusted PCASP data. The higher estimate is probably an overestimation of the average density, as the PCASP size bins were 


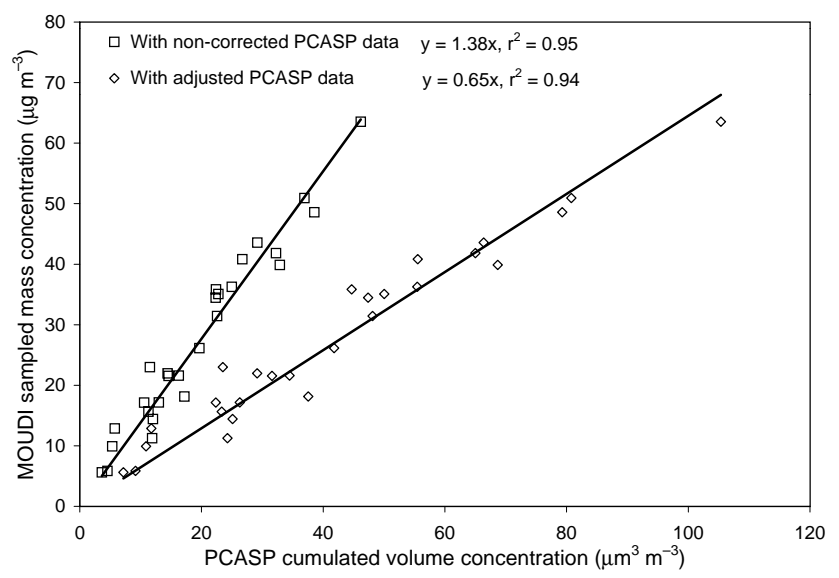

Fig. 7. Scatter plot of integrated volume concentrations obtained from a PCASP instrument against the MOUDI mass concentrations within a size range of $0.1-1 \mu \mathrm{m}$ for the LBA-EUSTACH 2 campaign. The open squares were obtained using the volume concentrations derived directly from the "raw" PCASP size distributions, the open diamonds using the volume concentrations derived after adjustment of the PCASP size bins for the refractive index of the sampled aerosol $(1.41-0.013 i)$.

not corrected for the refractive index, and the particle volume increases with the third power of this correction. On the other hand, the lower value could be an underestimation of the particle density because the PCASP was measuring ambient aerosols, whilst the MOUDI substrates were left equilibrating under controlled conditions of RH (50\%) and temperature $\left(20^{\circ} \mathrm{C}\right)$ for at least 24 hours prior to weighing, and volatile and semi-volatile constituents of the aerosol (including water) may have evaporated. These compounds may also have evaporated during daytime sampling, when the MOUDI was exposed to larger temperatures. However, it cannot be excluded that the correction for the refractive index applied to the PCASP overcorrects the data, resulting in an underestimation of the particle density.

Reid and Hobbs (1998) reported an average density for smoke particles $(D<4 \mu \mathrm{m})$ in Brazil of $1.35 \pm 0.15 \mathrm{~g} \mathrm{~cm}^{-3}$, with a technique similar to ours. However, their analysis comprised data for particles in the size range of 1-4 $\mathrm{m}$, and could therefore also include, for example, dust particles (uplifted by convection during a fire) whose specific density is larger than the biomass burning aerosols considered here. Martins et al. (1998) reported density values ranging between 1.00 and $1.21 \mathrm{~g} \mathrm{~cm}^{-3}$ for different types and ages of biomass burning aerosols in Brazil. Guyon et al. (2003) found a value of ca. $1.5 \mathrm{~g} \mathrm{~cm}^{-3}$ from a mass closure analysis of the LBA-EUSTACH 2 aerosol data $(D<2 \mu \mathrm{m})$. These authors noted, however, that this value might be an overestimation because voids and/or the water content of the aerosols were not taken into account, which would have lowered the density. Their calculations are also based on specific densi-

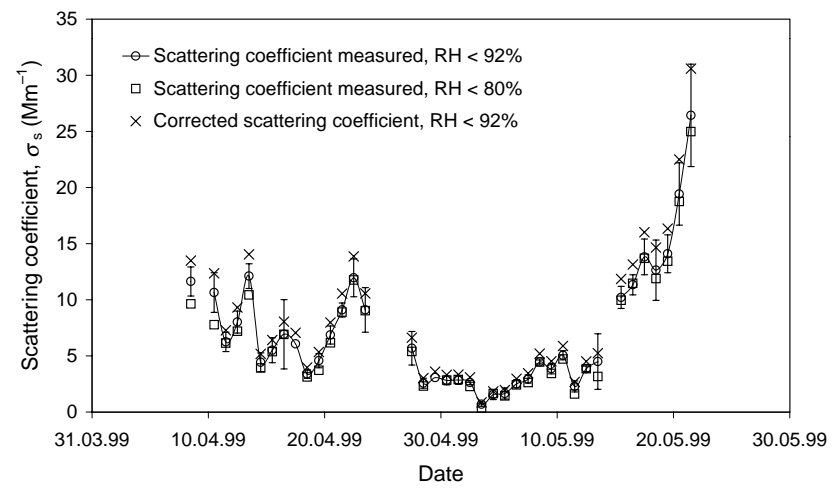

Fig. 8a. Daily averages of the scattering coefficients measured by a Radiance Research nephelometer $\left(\sigma_{s, \text { trunc }}\right)$, and of the scattering coefficients corrected for the truncation angles $\left(\sigma_{s}\right)$, during the LBA-EUSTACH 1 campaign. Values of $\sigma_{s}$ recorded at RH lower than $92 \%$ (crosses), $\sigma_{s, \text { trunc }}$ measured at RH lower than $80 \%$ (open squares) and $92 \%$ (open circles) are presented. The bars represent the standard deviation of the measurements.

ties for organics and black carbon estimated from literature values, which cover a broad range. A typical value often reported in the literature for the density of biomass burning aerosol particles is $1.0 \mathrm{~g} \mathrm{~cm}^{-3}$ (Radke et al., 1991), derived from the work of Stith et al. (1981). The latter authors determined the density of particles emitted from three prescribed burns of conifer slash by regressing a set of volume size distributions (obtained from an optical inversion technique) against mass size distributions. They retrieved values of $0.75,0.94$, and $1.34 \mathrm{~g} \mathrm{~cm}^{-3}$ for the three separate fires, and noted that these values were positively correlated with the fuel moisture content. However, we note here that the latter authors used the same method as ours, and the current estimate may be similar to theirs due to a method bias. Too little information on the density of this type of aerosol is available to date, resulting in large uncertainties in aerosol model calculations.

The regression of the five MOUDI samples collected in parallel to the PCASP during the LBA-EUSTACH 1 campaign yielded a density of $3.23 \mathrm{~g} \mathrm{~cm}^{-3}$ (standard error of $\left.0.08, r^{2}=0.99\right)$ using the uncorrected PCASP data, and $1.89 \mathrm{~g} \mathrm{~cm}^{3}$ (standard error of $0.10, r^{2}=0.99$ ) using the refractive index-adjusted PCASP data, for background aerosols of diameter $0.2-1 \mu \mathrm{m}$, over the Amazon basin. The higher values compared to the LBA-EUSTACH 2 campaign reflect the presence of particles such as dust grains, which form a proportionately greater fraction of the wet season aerosol (Artaxo et al., 1990; Echalar et al., 1998), and which have an aerosol density much larger than that of biomass burning particles. 


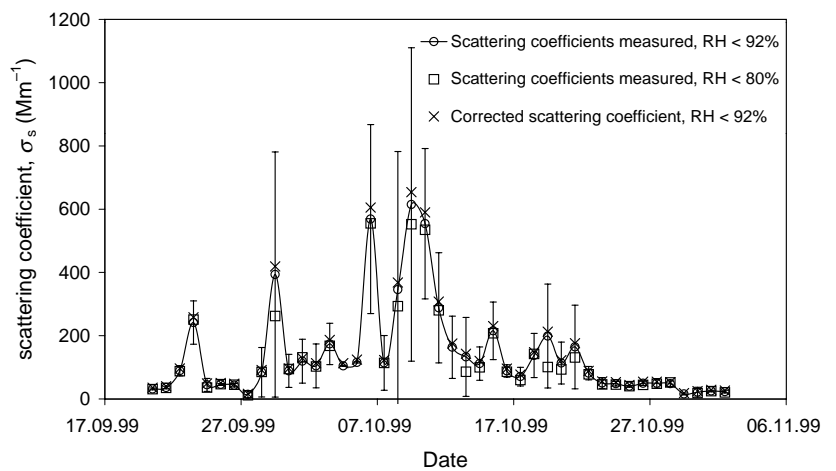

Fig. 8b. Daily averages of the scattering coefficients measured by a Radiance Research nephelometer $\left(\sigma_{s, \text { trunc }}\right)$, and of the scattering coefficients corrected for the truncation angles $\left(\sigma_{s}\right)$, during the LBA-EUSTACH 2 campaign. See caption to Fig. 8a for further details.

\subsection{Scattering coefficients}

Figures $8 \mathrm{a}$ and $8 \mathrm{~b}$ present daily averages of the scattering coefficients measured by the nephelometer for $\mathrm{RH}<92 \%$ and $\mathrm{RH}<80 \%$, together with the scattering coefficients corrected for truncation for the LBA-EUSTACH 1 and 2 campaigns, respectively. Scattering coefficients $\left(\sigma_{s}\right)$ recorded at $\mathrm{RH}>92 \%$ were removed from the data set because an ambient $\mathrm{RH}$ of $92 \%$ (equivalent to ca. $78 \%$ inside the instrument) was found to be the threshold value above which most scattering coefficient data showed a large response to increasing $\mathrm{RH}$ due to particle growth, at least for the LBA-EUSTACH 1 campaign. The presence of dense smoke plumes crossing the measurement site over almost the whole LBA-EUSTACH 2 campaign caused large variations in the measurements and made it more difficult to determine an upper RH limit for this season. Nevertheless, the aerosols exhibited reasonable properties up to an ambient $\mathrm{RH}$ of $92 \%$, and this value was therefore also chosen as the upper limit for this campaign. Because of the consistently very high $\mathrm{RH}$ observed at night during both campaigns (typically between 90 and 100\%), nighttime data are not presented.

Generally, it was observed that scattering coefficients increased with increasing $\mathrm{RH}$, beginning at values of ambient $\mathrm{RH}$ as low as $60 \%$, suggesting that the aerosols (especially during the first campaign) were taking up water even at moderate RH. Overall, the scattering coefficients measured at RH $<80 \%$ were only ca. $3 \%$ lower than those measured at $\mathrm{RH}$ $<92 \%$ for both the LBA-EUSTACH 1 and 2 campaigns. Daily averages of the corrected scattering coefficients measured during the first campaign at $\mathrm{RH}<92 \%$ were found to range from $0.9 \pm 0.7$ to $30.6 \pm 5.1 \mathrm{Mm}^{-1}$ (Fig. 8a). The $\sigma_{s}$ values increased sharply around 12 May 1999 , attributable to the increasing influence of biomass burning aerosols, together with the reduced precipitation rate toward the end of this campaign (see Sect. 3.1). The increase coincided with in-

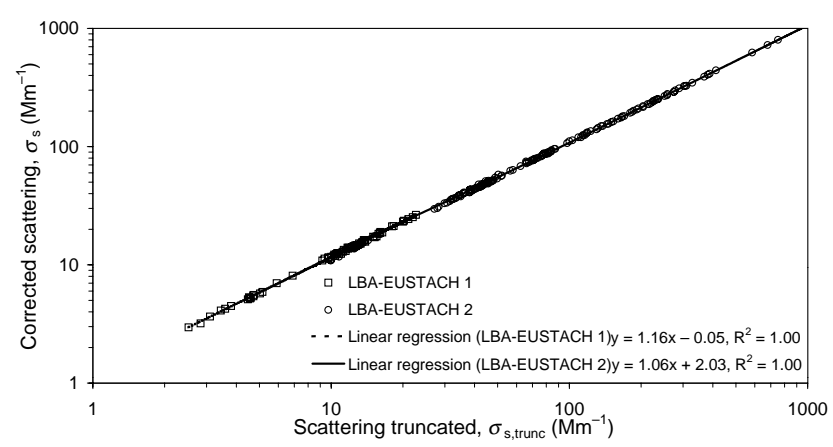

Fig. 9. Scatter plot of the truncation factor, $F_{\text {trunc }}$, defined as the ratio of $\sigma_{s}$ over $\sigma_{s, \text { trunc }}$ for both LBA-EUSTACH 1 and 2 campaigns. The least-square linear fit of the LBA-EUSTACH 1 (dotted line) and LBA-EUSTACH 2 (solid line) data are presented.

creased particle numbers measured by the CPC, with an overall correlation of $r^{2}=0.82$ between the truncation-corrected scattering coefficient and total particle concentration for the LBA-EUSTACH 1 campaign.

The average value of $\sigma_{s}$ for the period 8 April-12 May, which we consider to be representative for pristine background conditions, was $6.8 \pm 4.3 \mathrm{Mm}^{-1}$ (for ambient $\mathrm{RH}$ $<92 \%$ ). This is slightly lower than that measured by Formenti et al. (2001) (mean background ambient $\sigma_{s}$ of $10 \pm$ $1 \mathrm{Mm}^{-1}$ ) for the central Amazonian site of Balbina, in 1998, without applying an upper RH limit. This difference is probably due to the fact that the current study was performed at a more remote location. Our values are also about half those measured for clean marine boundary layer during the ACE-2 experiment (Collins et al., 2000).

In contrast to LBA-EUSTACH 1, the LBA-EUSTACH 2 campaign showed highly variable light scattering values (indicated in Fig. $8 \mathrm{~b}$ by the large standard deviation associated with the measurements), due to the frequent passage of biomass burning plumes over the measurement site. Daily averages of daytime values were found to vary between 16 and $654 \mathrm{Mm}^{-1}$, with an overall median value (first; third quartile) of $91 \mathrm{Mm}^{-1}(51 ; 201)$. These values fall within the lower range of scattering coefficients measured by Reid and Hobbs (1998) for younger plumes, in the direct vicinity of the fires. The data show a general increase in $\sigma_{s}$ values around 9 October, followed by a decrease that coincided with an observable decline in fire activity. The lowest values were mostly recorded after 23 October, which was a period characterized by increased rainfall. The scattering coefficient data followed a similar temporal trend to the CPC data, with an overall correlation of $r^{2}=0.53$ between the hourly-averaged scattering coefficient (truncation corrected) and total particle concentration for the LBA-EUSTACH 2 campaign.

Figure 9 presents a scatter plot of the corrected scattering coefficients, as obtained from the iteration calculation, against the truncated scattering coefficients for both LBA- 
EUSTACH 1 and 2 (for hourly averaged data measured at an ambient RH lower than 80\%). Linear regression yielded fitting equations of $\sigma_{s}=1.16 \sigma_{s, \text { trunc }}+0.05\left(r^{2}=1.00, n=64\right)$ and $\sigma_{s}=1.06 \sigma_{s, \text { trunc }}+2.03\left(r^{2}=1.00, n=170\right)$ (scattering coefficients in $\mathrm{Mm}^{-1}$ ) for LBA-EUSTACH 1 and 2, respectively (with $\mathrm{n}$ the total number of data points considered for each season). This indicates that, within the range of $\sigma_{s, \text { trunc }}$ observed for each season, not correcting for truncation leads to an error of ca. $16 \%$ for the LBA-EUSTACH 1 campaign, and ca. $6 \%$ for LBA-EUSTACH 2. We note here that inclusion of data collected between $80 \%$ and $92 \%$ RH did not produce a significant change in the regression parameters obtained.

We have performed a sensitivity study for the truncation factor, $F_{\text {trunc }}$, using the individual uncertainties associated with the measurements from the various instruments (see Guyon (2002) and Guyon et al. (2003) for a detailed description of the sensitivity test). We found the slope $\left(F_{\text {trunc }}\right)$ to be virtually insensitive to changes in any of the individual parameters. We can conclude that $F_{\text {trunc }}$ is constant over the whole range of scattering coefficients and particle number concentrations observed during both seasons, and is therefore only dependent on particle type and size. Our method for calculating the truncated part of the scattering coefficient obtained from an integrating nephelometer, therefore, appears very robust. Nevertheless, it should be noted that the lowest values measured during the second measurement campaign $\left(\sigma_{s, \text { trunc }}<\right.$ ca. $\left.30 \mathrm{Mm}^{-1}\right)$ do not lie on the linear fit obtained for this season, but tend to be closer to the one for the LBA-EUSTACH 1 data. The two equations found for the truncation factor agree well with those found by Anderson et al. (1996), if we consider that the LBA-EUSTACH 2 campaign was largely dominated by submicron smoke particles, whereas the LBA-EUSTACH 1 campaign included a large contribution of supermicrometer particles (Sect. 3.3).

\subsection{Absorption coefficients}

Daily averages of measured $\left(\sigma_{a, \text { meas }}\right)$ and Bond-corrected absorption coefficients $\left(\sigma_{a}\right)$ for the LBA-EUSTACH 1 and 2 campaigns are presented in Figs. 10a and b, respectively. Because the Bond correction of the PSAP data requires the use of simultaneously measured scattering coefficients, the corrected $\sigma_{a}$ were computed for RH $<92 \%$ only, in order to not overcorrect for the instrument response to scattering (see Sect. 3.4). The missing $\sigma_{a}$ values, comparing to $\sigma_{a \text {,meas }}$, are due to either the absence of scattering data or to extensive periods of $\mathrm{RH}>92 \%$, in which cases the Bond correction could not be applied to the PSAP data. Overall, absorption coefficients showed a similar temporal variation to the other aerosol properties that were measured. Daily averages of the values recorded during the first part of the LBA-EUSTACH 1 campaign were below $1.4 \pm 0.8 \mathrm{Mm}^{-1}$ (average of $0.4 \pm$ $0.5 \mathrm{Mm}^{-1}$ for the period 08 April-12 May 1999), increasing

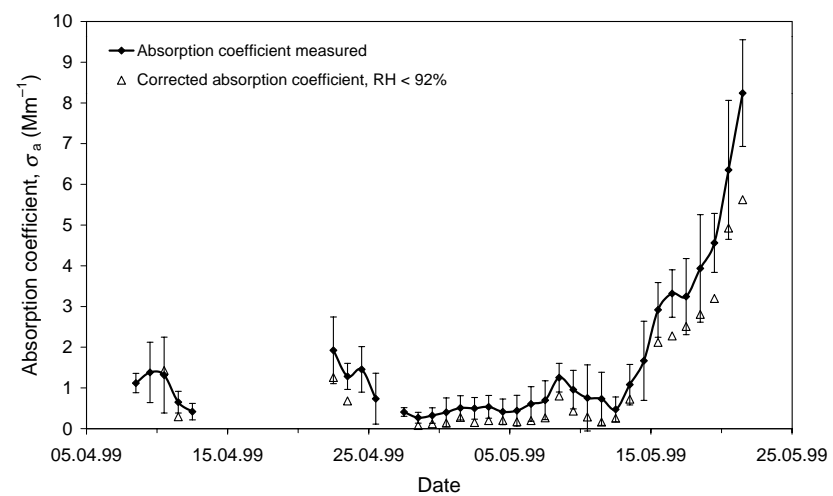

Fig. 10a. Daily averages of the absorption coefficients measured by a Radiance Research PSAP $\left(\sigma_{a}\right)$ during the LBA-EUSTACH 1 campaign. The vertical bars represent the standard deviation of the measurements.

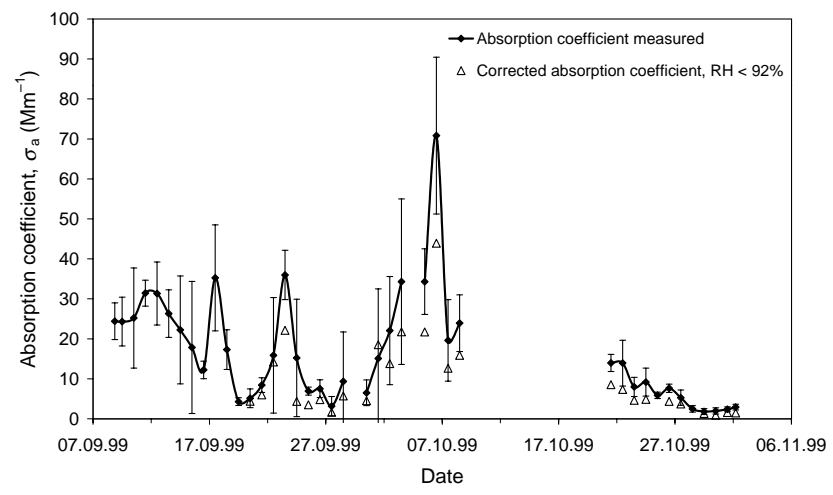

Fig. 10b. Daily averages of the absorption coefficients measured by a Radiance Research PSAP $\left(\sigma_{a}\right)$ during the LBA-EUSTACH 2 campaign. The vertical bars represent the standard deviation of the measurements.

to a value of $5.6 \pm 0.5 \mathrm{Mm}^{-1}$ (on 21 May 1999) when aged biomass burning smoke began reaching the site.

Our background values are lower than the ones reported by Artaxo et al. (2002) for the same campaign. An aethalometer situated at a pasture site $80 \mathrm{~km}$ away from the forest site measured $0.19 \pm 0.22 \mu \mathrm{g} \mathrm{m}^{-3}$ of absorbing material on average, corresponding to a $\sigma_{a}$ value of $1.9 \pm 2.2 \mathrm{Mm}^{-1}$, assuming an absorption cross section of $10 \mathrm{~m}^{2} \mathrm{~g}^{-1}$. However, their measurements were more influenced by local anthropogenic pollution. This is supported by higher particle concentrations measured with a CPC at the pasture site $\left(890 \pm 920 \mathrm{~cm}^{-3}\right)$ compared to the tower site (median of ca. $400 \mathrm{~cm}^{-3}$ ), indicating that the conditions encountered at the tower site during the LBA-EUSTACH 1 campaign were closer to pristine background conditions.

During LBA-EUSTACH 2, absorption coefficients fluctuated, as all other aerosol characteristics did, depending on local meteorology and biomass burning activity. A large dayto-day variation is noticeable from Fig. 10b, as well as a 


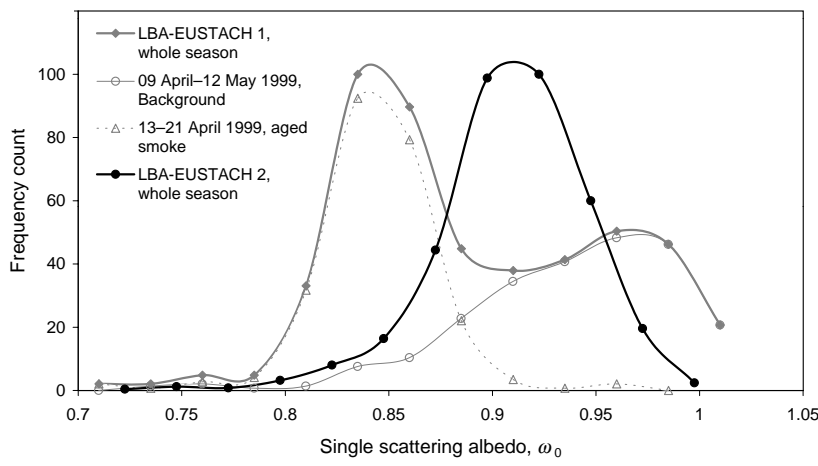

Fig. 11. Frequency plot of the single-scattering albedo, $\omega_{0}$, calculated for the LBA-EUSTACH 1 (gray lines and symbols) and LBAEUSTACH 2 (black line and symbols) campaigns. The $y$-axis scale is normalized to 100 at the highest frequency bin for each campaign. The symbols represent the center of the different frequency bins. The LBA-EUSTACH 1 data set has been separated into two parts: 9 April-12 May 1999 (open circles and light gray line) and 13-21 April 1999 (open triangles and light gray dashed line).

large within-day variation, indicated by the large measurement standard deviations. We observed an overall median (first; third quartile) $\sigma_{a}$ value of ca. $4.8 \mathrm{Mm}^{-1}(2.8 ; 8.6)$, peaking at ca. $70-90 \mathrm{Mm}^{-1}$ for short periods of time on 6 Oct 1999.

\subsection{Single-scattering albedo}

By combining measurements of scattering coefficients corrected for the truncation $\left(\sigma_{s}\right)$, and absorption coefficients $\left(\sigma_{a}\right)$, an estimate of the single-scattering albedo, $\omega_{0}$, for a wavelength of $550 \mathrm{~nm}$ could be obtained according to:

$\omega_{0}=\frac{\sigma_{s}}{\sigma_{s}+\sigma_{a}}$

Figure 11 presents a frequency plot of the single-scattering albedo measured over both field campaigns when ambient $\mathrm{RH}$ was below $80 \%$, relative to the maximum frequency value for each campaign. The errors associated with the single-scattering albedo measurements were obtained by error propagation, using an error of $5 \%$ for the nephelometer (Sect. 2.4) and $20 \%$ for the PSAP (the largest possible absolute error associated with this instrument) (Bond et al., 1999). Because the error in $\sigma_{a}$ is larger than that in $\sigma_{s}$, the error in $\omega_{0}$ increases with decreasing values of $\omega_{0}$. We found absolute errors ranging from \pm 0.01 , for the beginning of the first campaign, to \pm 0.03 towards the end of this campaign. Errors in $\omega_{0}$ for the LBA-EUSTACH 2 campaign ranged between these two values. Note should be taken that correcting the PSAP data according to Bond et al. (1999) created ca. $3 \%$ of artifact negative $\sigma_{a}$ values at $\mathrm{RH}<80 \%$ during LBAEUSTACH 1, and, therefore corresponding $\omega_{0}$ values larger than unity. This was already observed by Anderson et al.
(1999), and could be an indication that the Bond correction may overcorrect the PSAP data in some cases. However, this pattern was not observed during the LBA-EUSTACH 2 campaign, when absorption coefficients were larger overall.

It is clear from Figure 11 that the LBA-EUSTACH 1 campaign showed two distinct frequency maxima. The first period of the campaign (9 April-12 May 1999), characteristic of pristine background conditions, showed a maximum at $\omega_{0}=0.97$. For a comparison, Carrico et al. (2000) found $\omega_{0}$ values centered around $0.95 \pm 0.04$ at $550 \mathrm{~nm}$ for clean marine air, at comparable ambient $\mathrm{RH}$ and using a similar instrumentation to ours. However, the whole campaign period exhibited a median $\omega_{0}$ value (first; third quartile) of only $0.95(0.90 ; 0.98)$ due to some biomass burning-influenced episodes occurring throughout the campaign. The singlescattering albedo dropped dramatically from 13 May 1999 onwards, when aged biomass smoke reached the site, to values centered at $\omega_{0}=0.84(0.83 ; 0.86)$. It is important to note that for Fig. 11 the apparent higher frequency of low $\omega_{0}$ values (observed predominantly during the second part of the LBA-EUSTACH 1 campaign) is an artifact arising from the large fraction of the background $\omega_{0}$ values that had to be discarded from the analysis because of the high ambient $\mathrm{RH}$ at which they were measured.

Ackerman et al. (2000) found in a model study of similar absorbing aerosols $\left(\omega_{0}=0.88\right.$ at $\left.500 \mathrm{~nm}\right)$ that a modest number concentration increase, comparable to the one we observed, may result in a dramatic alteration of radiative forcing through cloud evaporation. Thus, even the modest increase in particle number concentration observed between 13-21 May 1999, resulting from diluted plumes arriving from fire sources some 2-3 days away from the sampling site (Fig. 1), may potentially have a significant bearing on climatic and water cycle processes occurring within the region.

It is interesting to note that for the biomass burning haze period (LBA-EUSTACH 2), the median single-scattering albedo $\left(\omega_{0}=0.91(0.89 ; 0.93)\right)$ was found to be higher than that observed at the end of the first campaign. This could be attributable to the formation of a shell around a soot core for aged smoke plume particles, which would have enhanced the absorption properties of the aerosols sampled during the second part of the LBA-EUSTACH 1 campaign relative to those sampled during LBA-EUSTACH 2 (Hallett et al., 1989; Horvath, 1993; Martins et al., 1998). It is also noted here that the same central value of $0.91(0.90 ; 0.93)$ was found for this season when using only the PSAP data obtained for filter transmittance $>0.7$, and that the lower sensitivity of the instrument at lower transmittance was not responsible for significant differences in the reported value.

The aerosol community has recently become aware of a possible systematic discrepancy between values of $\omega_{0}$ measured in situ and those retrieved from remote sensing data. For example, in situ measurements performed by Reid et al. (1998) during SCAR-B yielded average $\omega_{0}$ values of 0.79 
for young plumes and regional haze, and 0.83-0.86 for aged haze (at $550 \mathrm{~nm}$ ). Somewhat controversially, Remer et al. (1998) argued that such low values could not be reconciled with sky radiance data obtained during the same experiment, and gave a $\omega_{0}$ estimate of 0.90 at $550 \mathrm{~nm}$. Other sky radiance measurements of biomass burning haze during SCAR-B yielded $\omega_{0}$ values ranging from approximately 0.82 to 0.94 (Eck et al., 1998). More recently, Dubovik et al. (2002) used sky radiance data to estimate $\omega_{0}$ values of ca. $0.94 \pm$ 0.02 at $440 \mathrm{~nm}$ and $0.93 \pm 0.02$ at $670 \mathrm{~nm}$ for biomass burning aerosols found over the Amazonian rainforest, and ca. 0.90 for smoke aerosol produced by the burning of Brazilian cerrado. Remote sensing techniques based on upward radiance, usually involving satellite sensors, show typically even higher $\omega_{0}$ values. Kaufman et al. (1990), for instance, reported an average $\omega_{0}$ value of 0.98 for forest fire aerosol in Rondônia between mid-visible $(630 \mathrm{~nm})$ and near-infrared $(840 \mathrm{~nm})$ wavelengths. More recently, Li et al. (2000) used in situ-measured $\omega_{0}$ values (e.g., $\omega_{0}=0.88$ for forest fire) from the SCAR-B experiment to retrieve aerosol optical depth from satellite data. Wong and Li (2002), however, argued that the aerosol properties (single-scattering albedo and asymmetry parameter) reported from various field experiments cannot be used to retrieve comparable aerosol optical depth. They found that in order to use a $\omega_{0}$ of ca. 0.87 for forest fire aerosols in their model, the asymmetry parameter would have to be substantially decreased to values $<0.4$ at $650 \mathrm{~nm}$ (a typical value is 0.57 at this wavelength). Our in situ $\omega_{0}$ measurements for biomass burning haze are higher than those reported by Reid et al. (1998), but are still in the lower range of most of those derived from remote sensing measurements. Certainly our correction of the nephelometer data toward larger values, together with the Bond correction of the PSAP absorption coefficients, contributed toward reducing this discrepancy. Nevertheless, the disparity in $\omega_{0}$ estimates obtained from remote sensing and in situ methods remains unexplained and requires further investigation, especially given that the derivation of accurate aerosol radiative forcing estimates is dependent upon this parameter.

Although an estimate of the aerosol layer radiative forcing is far beyond the scope of this paper, the sign of the top-ofatmosphere (TOA) forcing can be estimated. The boundary between cooling and heating can be given relative to a critical single-scattering albedo, $\omega_{c r i t}$, as a function of the surface albedo, $R_{S}$, and the upscatter fraction, $\beta$ (Seinfeld and Pandis, 1998):

$\omega_{c r i t}=\frac{2 R_{s}}{2 R_{s}+\beta\left(1-R_{S}\right)^{2}}$

where values of $\omega_{0}>\omega_{\text {crit }}$ lead to a net cooling.

Ross et al. (1998) reported $R_{S}$ values of 0.05 for tropical forest, and 0.06 for the reflectance of the ocean, at wavelengths between 500 and $700 \mathrm{~nm}$. We have derived estimates of $\beta$ from Mie scattering calculations, for a solar zenith angle $\theta_{0}=0^{\circ}$ (i.e., the backscattered fraction) (Guyon et al.,
2003). Average $\beta$ values of $0.12 \pm 0.01,0.10 \pm 0.01$, and $0.08 \pm 0.01$ were found for the first and second periods of the LBA-EUSTACH 1 campaign, and LBA-EUSTACH 2, respectively. Consequently, in our case the value of $\omega_{\text {crit }}$ would be $0.46-0.61$ over tropical forest and $0.51-0.66$ over the ocean, leading to a net cooling by the aerosols for both environments. We note here that at increasing solar zenith angle, $\beta$ would increase, decreasing further $\omega_{\text {crit }}$. Therefore, even when biomass burning dominates the aerosol loading and $\omega_{0}$ decreases, the sign of the TOA forcing remains negative, although its amplitude may vary. This effect is certainly due to the very low $R_{s}$ values characteristic for evergreen forests and oceans. Applying a typical global mean $R_{S}$ of about 0.15 would lead to an almost negligible effect at TOA for the aged haze at the end of the first campaign, and a net cooling for the regional biomass burning haze (at a solar zenith angle of $0^{\circ}$ ). Biomass burning aerosol over cerrado, with an $R_{s}$ value of ca. 0.11 , would lead to similar effects.

\section{Conclusions}

In this manuscript, we have described the main physical characteristics of Amazonian aerosols and their abundance for both the wet and dry seasons, as well as during the transition periods between the seasons. It is clearly evident from the data set that anthropogenic biomass burning activities have a dramatic impact on the total aerosol loading, even above a remote site located within a primary rainforest reserve. Scattering and absorption by even relatively modest amounts of smoke aerosol overwhelms the effects of the background aerosol, which is present at very low concentrations during the wet season under unpolluted conditions. The potential certainly exists for these changes to alter the radiation balance, as well as cloud formation and rain-out processes, and thus the whole hydrological cycle in the Amazon basin. However, whilst the data attest to the significant difference between biomass burning and background atmospheric conditions, the actual climatic impacts of burning activities remain uncertain. For instance, the values of $\omega_{0}$ for forest fires cover a wide range and could lead to a prediction of a considerable warming or cooling effect by biomass burning aerosol, depending on which values are chosen. Thus, we consider it vital that intensive research efforts continue to be directed toward more accurate measurements of absorption and single-scattering albedo. Such studies are critical not only for the Amazon region, but also from a global perspective, due to the fact that the large-scale atmospheric circulation in the tropics may mean that the products of burning activities can be carried to higher latitudes, where their climatic effects may also be significant (Andreae, 1991; Pickering et al., 1996; Andreae and Merlet, 2001; Andreae et al., 2001). 
Acknowledgements. This work was carried out within the frame of the EUropean Studies on Trace gases and Atmospheric CHemistry (EUSTACH), a European contribution to the Large-Scale Biosphere-Atmosphere Experiment in Amazonia (LBA). It was financially supported by the Max Planck Society (MPG) and the Environmental and Climate Program of the European Union commission. P. Artaxo acknowledges FAPESP and the MCT program Millenium Institute for funding. The authors acknowledge MCT/INPE/CPTEC for providing the fire pixels data, and C. Ammann and U. Rummel for providing the local meteorological data.

\section{References}

Ackerman, A. S., Toon, O. B., Stevens, D. E., Heymsfield, A. J., Ramanathan, V., and Welton, E. J.: Reduction of tropical cloudiness by soot, Science, 288, 1042-1047, 2000.

Anderson, T. L., Covert, D. S., Marshall, S. F., Laucks, M. L., Charlson, R. J., Waggoner, A. P., Ogren, J. A., Caldow, R., Holm, R. L., Quant, F. R., Sem, G. J., Wiedensohler, A., Ahlquist, N. A., and Bates, T. S.: Performance characteristics of a high-sensitivity, three-wavelength, total scatter/backscatter nephelometer, J. Atmos. Ocean. Technol., 13, 967-986, 1996.

Anderson, T. L., Covert, D. S., Wheeler, J. D., Harris, J. M., Perry, K. D., Trost, B. E., Jaffe, D. J., and Ogren, J. A.: Aerosol backscatter fraction and single scattering albedo: Measured values and uncertainties at a coastal station in the Pacific Northwest, J. Geophys. Res.-Atmos., 104, 26 793-26 807, 1999.

Andreae, M. O.: Biomass burning: Its history, use, and distribution and its impacts on environmental quality and global climate, in Global biomass burning: Atmospheric, climatic, and biospheric implications, J. S. Levine (Ed), pp. 3-21, MIT Press, Cambridge, Mass., 1991.

Andreae, M. O., Artaxo, P., Brandao, C., Carswell, F. E., Ciccioli, P., Costa, A. L. D., Culf, A. D., Esteves, J. L., Gash, J. H. C., Grace, J., Kabat, P., Lelieveld, J., Malhi, Y., Manzi, A. O., Meixner, F. X., Nobre, A. D., Nobre, C., Ruivo, M. D. L. P., Silva-Dias, M. A., Stefani, P., Valentini, R., Jouanne, J. V., and Waterloo, M. J.: Towards an understanding of the biogeochemical cycling of carbon, water, energy, trace gases and aerosols in Amazonia: The LBA-EUSTACH experiment, J. Geophys. Res.Atmos., 107, 8066, doi: 8010.1029/2001JD000524, 2002.

Andreae, M. O., Artaxo, P., Fischer, H., Freitas, S. R., Gregoire, J. M., Hansel, A., Hoor, P., Kormann, R., Krejci, R., Lange, L., Lelieveld, J., Lindinger, W., Longo, K., Peters, W., de Reus, M., Scheeren, B., Dias, M., Strm, J., van Velthoven, P. F. J., and Williams, J.: Transport of biomass burning smoke to the upper troposphere by deep convection in the equatorial region, Geophys. Res. Lett., 28, 951-954, 2001.

Andreae, M. O. and Crutzen, P. J.: Atmospheric aerosols: Biogeochemical sources and role in atmospheric chemistry, Science, 276, 1052-1058, 1997.

Andreae, M. O. and Merlet, P.: Emission of trace gases and aerosols from biomass burning, Global Biogeochemical Cycles, 15, 955966, 2001.

Artaxo, P. and Hansson, H. C.: Size distribution of biogenic aerosolparticles from the amazon basin, Atmos. Environ., 29, 393-402, 1995.

Artaxo, P., Maenhaut, W., Storms, H., and van Grieken, R.: Aerosol characteristics and sources for the Amazon basin during the wet season, J. Geophys. Res. Atmos., 95, 16971-16 985, 1990.

Artaxo, P., Martins, J. V., Yamasoe, M. A., Procópio, A. S., Pauliquevis, T. M., Andreae, M. O., Guyon, P., Gatti, L. V., and Leal, A. M. G.: Physical and chemical properties of aerosols in the wet and dry season in Rondnia, Amazonia, J. Geophys. Res. Atmos., 107, 8081, doi:8010.1029/2001JD000666, 2002.

Bond, T. C., Anderson, T. L., and Campbell, D.: Calibration and intercomparison of filter-based measurements of visible light absorption by aerosols, Aerosol Sci. Technol., 30, 582-600, 1999.

Carrico, C. M., Rood, M. J., Ogren, J. A., Neususs, C., Wiedensohler, A., and Heintzenberg, J.: Aerosol optical properties at Sagres, Portugal during ACE-2, Tellus Ser. B-Chem. Phys. Meteorol., 52, 694-715, 2000.

Collins, D. R., Jonsson, H. H., Seinfeld, J. H., Flagan, R. C., Gasso, S., Hegg, D. A., Russell, P. B., Schmid, B., Livingston, J. M., Ostrom, E., Noone, K. J., Russell, L. M., and Putaud, J. P.: In situ aerosol-size distributions and clear-column radiative closure during ACE-2, Tellus Ser. B-Chem. Phys. Meteorol., 52, 498525, 2000.

Draxler, R. R. and Hess, G. D.: An overview of the HYSPLIT 4 modelling system for trajectories, dispersion, and deposition, Australian Meteorological Magazine, 47, 295-308, 1998.

Dubovik, O., Holben, B., Eck, T. F., Smirnov, A., Kaufman, Y. J., King, M. D., Tanré, D., and Slutsker, I.: Variability of absorption and optical properties of key aerosol types observed in worldwide locations, J. Atmos. Sci., 59, 590-608, 2002.

Echalar, F., Artaxo, P., Martins, J. V., Yamasoe, M., Gerab, F., Maenhaut, W., and Holben, B.: Long-term monitoring of atmospheric aerosols in the Amazon basin: Source identification and apportionment, J. Geophys. Res. Atmos., 103, 31 849-31 864, 1998.

Eck, T. F., Holben, B. N., Slutsker, I., and Setzer, A.: Measurements of irradiance attenuation and estimation of aerosol single scattering albedo for biomass burning aerosols in Amazonia, J. Geophys. Res.-Atmos., 103, 31 865-31 878, 1998.

Finlayson-Pitts, B. J. and Pitts, J. N.: Chemistry of the upper and lower atmosphere theory, experiments and applications, Academic Press, San Diego, 2000.

Fisch, G., Tota, J., Machado, L. A. T., Silva Dias, M. A. F., Lyra, R. F. d. F., Nobre, C. A., Dolman, A. J., and Gash, J. H. C.: The convective boundary layer over pasture site and forest in Amazonia, Theoretical and Applied Climatology, submitted, 2003.

Fitzgerald, J. W.: Marine aerosols - a review, Atmos. Environ. Part A-General Topics, 25, 533-545, 1991.

Formenti, P., Andreae, M. O., Lange, L., Roberts, G., Cafmeyer, J., Rajta, I., Maenhaut, W., Holben, B. N., Artaxo, P., and Lelieveld, J.: Saharan dust in Brazil and Suriname during the large-scale biosphere-atmosphere experiment in Amazonia (LBA) - cooperative LBA regional experiment (CLAIRE) in March 1998, J. Geophys. Res.-Atmos., 106, 14 919-14 934, 2001.

Formenti, P., Andreae, M. O., and Lelieveld, J.: Measurements of aerosol optical depth above $3570 \mathrm{~m}$ asl in the North Atlantic free troposphere: Results from ACE-2, Tellus Ser. B-Chem. Phys. Meteorol., 52, 678-693, 2000.

Guyon, P.: Chemical and physical properties of Amazonian aerosol particles, PhD Thesis, Johannes Gutenberg-Universität Mainz and Université de Paris VII-Denis Diderot, Mainz and Paris, pp. 220, URL: http://ArchiMeD.uni-mainz.de/pub/2003/0035, 2002. 
Guyon, P., Boucher, O., Graham, B., Beck, J., Mayol-Bracero, O. L., Roberts, G. C., Maenhaut, W., Artaxo, P., and Andreae, M. O.: Refractive index of aerosol particles over the Amazon tropical forest during LBA-EUSTACH 1999, J. Aerosol Sci., 34, 883907, 2003.

Hallett, J., Hudson, J. G., and Rogers, C. F.: Characterization of combustion aerosols for haze and cloud formation, Aerosol Sci. Technol., 10, 70-83, 1989.

Harrison, L. and Michalsky, J.: Objective algorithms for the retrieval of optical depths from ground-based measurements, Appl. Optics, 33, 5126-5132, 1994.

Harrison, L., Michalsky, J., and Berndt, J.: Automated multifilter rotating shadow-band radiometer - an instrument for optical depth and radiation measurements, Appl. Optics, 33, 5118-5125, 1994.

Harriss, R. C., Garstang, M., Wofsy, S. C., Beck, S. M., Bendura, R. J., Coelho, J. R. B., Drewry, J. W., Hoell, J. M., Matson, P. A., McNeal, R. J., Molion, L. C. B., Navarro, R. L., Rabine, V., and Snell, R. L.: The Amazon boundary-layer experiment - wet season 1987, J. Geophys. Res.-Atmos., 95, 16721-16 736, 1990.

Harriss, R. C., Wofsy, S. C., Garstang, M., Browell, E. V., Molion, L. C. B., McNeal, R. J., Hoell, J. M., Bendura, R. J., Beck, S. M., Navarro, R. L., Riley, J. T., and Snell, R. L.: The Amazon boundary-layer experiment (ABLE-2a) - dry season 1985, J. Geophys. Res.-Atmos., 93, 1351-1360, 1988.

Hedberg, E., Kristensson, A., Ohlsson, M., Johansson, C., Johansson, P. A., Swietlicki, E., Vesely, V., Wideqvist, U., and Westerholm, R.: Chemical and physical characterization of emissions from birch wood combustion in a wood stove, Atmos. Environ., 36, 4823-4837, 2002.

Hinds, W. C.: Aerosol technology: Properties, behavior, and measurement of airbone particles, Wiley-Interscience, New York, 1999.

Holben, B. N., Eck, T. F., Slutsker, I., Tanré, D., Buis, J. P., Setzer, A., Vermote, E., Reagan, J. A., Kaufman, Y. J., Nakajima, T., Lavenu, F., Jankowiak, I., and Smirnov, A.: AERONET - a federated instrument network and data archive for aerosol characterization, Remote Sens. Environ., 66, 1-16, 1998.

Horvath, H.: Atmospheric light-absorption - a review, Atmospheric Environment Part a-General Topics, 27, 293-317, 1993.

Horvath, H.: Influence of atmospheric aerosols upon the global radiation balance, in Atmospheric particles, edited by R. M. Harrison, and R. Van Grieken, pp. 543-596, John Wiley \& Sons Ltd., 1998.

IPCC: Climate change 2001: The third assessment report to the intergovernmental panel on climate change, Cambridge University Press, Cambridge, United kingdom, and New York, NY, USA, 2001.

Jacob, D. J. and Wofsy, S. C.: Photochemistry of biogenic emissions over the Amazon forest, J. Geophys. Res. Atmos., 93, 14771486, 1988.

Jacob, D. J. and Wofsy, S. C.: Budgets of reactive nitrogen, hydrocarbons, and ozone over the Amazon-forest during the wet season, J. Geophys. Res. Atmos., 95, 16737-16 754, 1990.

Kaufman, Y. J., Hobbs, P. V., Kirchhoff, V., Artaxo, P., Remer, L. A., Holben, B. N., King, M. D., Ward, D. E., Prins, E. M., Longo, K. M., Mattos, L. F., Nobre, C. A., Spinhirne, J. D., Ji, Q., Thompson, A. M., Gleason, J. F., Christopher, S. A., and Tsay, S. C.: Smoke, Clouds, and Radiation - Brazil (SCAR-B) experiment, J. Geophys. Res.-Atmos., 103, 31 783-31 808, 1998.

Kaufman, Y. J., Tucker, C. J., and Fung, I.: Remote-sensing of biomass burning in the tropics, J. Geophys. Res.-Atmos., 95, 9927-9939, 1990.

Le Canut, P., Andreae, M. O., Harris, G. W., Wienhold, F. G., and Zenker, T.: Air-borne studies of emissions from savanna fires in Southern Africa .1. Aerosol emissions measured with a laser optical particle counter, J. Geophys. Res. Atmos., 101, 23615 23 630, 1996.

Li, X., Christopher, S. A., Chou, J., and Welch, R. M.: Estimation of shortwave direct radiative forcing of biomass-burning aerosols using new angular models, J. Appl. Meteorol., 39, 2278-2291, 2000.

Marple, V. A., Rubow, K. L., and Behm, S. M.: A microorifice uniform deposit impactor (MOUDI) - description, calibration, and use, Aerosol Sci. Technol., 14, 434-446, 1991.

Martins, J. V., Artaxo, P., Liousse, C., Reid, J. S., Hobbs, P. V., and Kaufman, Y. J.: Effects of black carbon content, particle size, and mixing on light absorption by aerosols from biomass burning in Brazil, J. Geophys. Res.-Atmos., 103, 32 041-32 050, 1998.

Nobre, C. A., Wickland, D., and Kabat, P.: The large scale biosphere-atmosphere experiment in Amazonia (LBA), IGBP newsletter, 45, 2001.

Pickering, K. E., Thompson, A. M., Wang, Y. S., Tao, W. K., McNamara, D. P., Kirchhoff, V., Heikes, B. G., Sachse, G. W., Bradshaw, J. D., Gregory, G. L., and Blake, D. R.: Convective transport of biomass burning emissions over Brazil during TRACE A, J. Geophys. Res. Atmos., 101, 23 993-24 012, 1996.

Radke, L. F., Hegg, A. S., Hobbs, P. V., and Penner, J. E.: Effects of aging on the smoke from a large forest-fire, Atmos. Res., 38, 315-332, 1995 .

Radke, L. F., Hegg, D. A., Hobbs, P. V., Nance, J. D., Lyons, J. H., Laursen, K. K., Weiss, R. E., Riggan, P. J., and Ward, D. E.: Particulates and trace gas emissions from large biomass fires in north America, in Global biomass burning: Atmospheric, climatic, and biospheric implications, J. S. Levine (Ed), MIT Press, Cambridge, Mass., pp. 209-224, 1991.

Raes, F., Van Dingenen, R., Vignati, E., Wilson, J., Putaud, J. P., Seinfeld, J. H., and Adams, P.: Formation and cycling of aerosols in the global troposphere, Atmos. Environ., 34, 4215-4240, 2000.

Reid, J. S. and Hobbs, P. V.: Physical and optical properties of young smoke from individual biomass fires in Brazil, J. Geophys. Res.-Atmos., 103, 32 013-32 030, 1998.

Reid, J. S., Hobbs, P. V., Ferek, R. J., Blake, D. R., Martins, J. V., Dunlap, M. R., and Liousse, C.: Physical, chemical, and optical properties of regional hazes dominated by smoke in Brazil, J. Geophys. Res. Atmos., 103, 32 059-32 080, 1998.

Remer, L. A., Kaufman, Y. J., Holben, B. N., Thompson, A. M., and McNamara, D.: Biomass burning aerosol size distribution and modeled optical properties, J. Geophys. Res.-Atmos., 103, 31 879-31 891, 1998.

Roberts, M. C., Andreae, M. O., Zhou, J. C., and Artaxo, P.: Cloud condensation nuclei in the Amazon Basin: "Marine" conditions over a continent?, Geophys. Res. Lett., 28, 2807-2810, 2001.

Roberts, G. C., Artaxo, P., Zhou, J., Swietlicki, E., and Andreae, M. O.: Sensitivity of CCN spectra on chemical and physical properties of aerosols: A case study from the Amazon basin, J. Geophys. Res. Atmos., 107, 8070, doi: 10.1029/2001JD000583, 2002. 
Ross, J. L., Hobbs, P. V., and Holben, B.: Radiative characteristics of regional hazes dominated by smoke from biomass burning in Brazil: Closure tests and direct radiative forcing, J. Geophys. Res.-Atmos., 103, 31 925-31 941, 1998.

Seinfeld, J. H. and Pandis, S. N.: Atmospheric chemistry and physics, Wiley-Interscience, New York, 1998.

Shine, K. P. and Forster, P. M. D.: The effect of human activity on radiative forcing of climate change: A review of recent developments, Glob. Planet. Change, 20, 205-225, 1999.

Staudt, A. C., Jacob, D. J., Logan, J. A., Bachiochi, D., Krishnamurti, T. N., and Sachse, G. W.: Continental sources, transoceanic transport, and interhemispheric exchange of carbon monoxide over the pacific, J. Geophys. Res. Atmos., 106, 32 571-32 589, 2001.

Stith, J. L., Radke, L. F., and Hobbs, P. V.: Particle emissions and the production of ozone and nitrogen oxides from the burning of forest slash, Atmos. Environ., 15, 73-82, 1981.

Williams, E., Rosenfeld, D., Madden, N., Gerlach, J., Gears, N., Atkinson, L., Dunnemann, N., Frostrom, G., Antonio, M., Biazon, B., Camargo, R., Franca, H., Gomes, A., Lima, M.,
Machado, R., Manhaes, S., Nachtigall, L., Piva, H., Quintiliano, W., Machado, L., Artaxo, P., Roberts, G., Renno, N., Blakeslee, R., Bailey, J., Boccippio, D., Betts, A., Wolff, D., Roy, B., Halverson, J., Rickenbach, T., Fuentes, J., and Avelino, E.: Contrasting convective regimes over the amazon: Implications for cloud electrification, J. Geophys. Res. Atmos., 107, 8082, doi:8010.1029/2001JD000380, 2002.

Winklmayr, W., Wang, H. C., and John, W.: Adaptation of the Twomey algorithm to the inversion of cascade impactor data, Aerosol Sci. Technol., 13, 322-331, 1990.

Wong, J. and Li, Z. Q.: Retrieval of optical depth for heavy smoke aerosol plumes: Uncertainties and sensitivities to the optical properties, J. Atmos. Sci., 59, 250-261, 2002.

Zhou, J., Swietlicki, E., Hansson, H. C., and Artaxo, P.: Sub-micrometer aerosol particle size distribution and hygroscopic growth measured in the Amazon rain forest during the wet season, J. Geophys. Res. Atmos., 107, 8055, doi: 10.1029/2000JD000203, 2002. 